\title{
Regulation and roles of bicarbonate transporters in cancer
}

\author{
Andrej Gorbatenko', Christina W. Olesen ${ }^{1}$, Ebbe Boedtkjer ${ }^{2}$ and Stine F. Pedersen ${ }^{1 *}$ \\ ${ }^{1}$ Department of Biology, University of Copenhagen, Copenhagen, Denmark \\ ${ }^{2}$ Department of Biomedicine, Aarhus University, Aarhus, Denmark
}

\section{Edited by:}

Mark Oliver Bevensee, University of

Alabama at Birmingham, USA

\section{Reviewed by:}

Alexi Alekov, Medizinische

Hochschule Hannover, Germany

Annarosa Arcangeli, University of

Florence, Italy

Jaromír Pastorek, Slovak Academy

of Sciences, Slovakia

\section{*Correspondence:}

Stine F. Pedersen, Department of

Biology, University of Copenhagen,

Universitetsparken 13, DK-2100

Copenhagen, Denmark

e-mail: sfpedersen@bio.ku.dk
A unifying feature of solid tumors is a markedly altered $\mathrm{pH}$ profile compared to normal tissues. This reflects that solid tumors, despite completely different origins, often share several phenotypic properties with implications for intra- and extracellular $\mathrm{pH}$. These include: a metabolic shift in most cancer cells toward more acid-producing pathways, reflecting both oncogenic signaling and the development of hypoxia in poorly perfused regions of the tumors; the poorly perfused and often highly dense tumor microenvironment, reducing the diffusive flux of acid equivalents compared to that in normal tissues; and the markedly altered regulation of the expression and activity of $\mathrm{pH}$-regulatory transport proteins in cancer cells. While some of these properties of tumors have been well described in recent years, the great majority of the research in this clinically important area has focused on proton transport, in particular via the $\mathrm{Na}^{+} / \mathrm{H}^{+}$exchanger 1 (SLC9A1, NHE1) and various $\mathrm{H}^{+}$ATPases. We have, however, recently demonstrated that at least under some conditions, including in vitro models of HER2 positive breast cancer, and measurements obtained directly in freshly dissected human mammary carcinomas, bicarbonate transporters such as the electroneutral $\mathrm{Na}^{+}, \mathrm{HCO}_{3}^{-}$cotransporter (SLC4A7, NBCn1), are upregulated and play central roles in $\mathrm{pH}$ regulation. In this review, we summarize and discuss the current knowledge regarding the regulation and roles of bicarbonate transporters in cancer. Furthermore, we present new analyses of publicly available expression data demonstrating widely altered expression levels of SLC4- and SLC26 family transporters in breast-, lung-, and colon cancer patients, and we hypothesize that bicarbonate transporter dysregulation may have both diagnostic and therapeutic potential in cancer treatment.

Keywords: NBCn1, DRA, ion transport, acid-base regulation, intracellular $\mathrm{pH}$

\section{INTRODUCTION AND OVERVIEW}

Intracellular $\mathrm{pH}\left(\mathrm{pH}_{\mathrm{i}}\right)$ homeostasis is a prerequisite for normal cell function and requires, under most conditions, net extrusion of acid equivalents to compensate for the metabolic acid production and the $\mathrm{H}^{+}$influx caused by the inwardly directed driving force for this ion. Within the last decade, numerous studies have demonstrated that $\mathrm{pH}_{\mathrm{i}}$ homeostasis is often dramatically altered in cancer (for reviews see Gatenby and Gillies, 2008; Webb et al., 2011; Boedtkjer et al., 2012; Parks et al., 2013; Pedersen and Stock, 2013). This has sparked substantial interest in $\mathrm{pH}$ regulation as a potential therapeutic target relevant to many forms of cancer. It has been demonstrated that the high metabolic demand of rapidly proliferating cancer cells, in conjunction with a shift toward glycolytic metabolism reflecting both tumor hypoxia and oncogene-induced changes in gene expression, leads to an often greatly increased production of acid equivalents in cancer cells (see Kroemer and Pouyssegur, 2008; Cairns et al., 2011; Cantor and Sabatini, 2012; Andersen et al., 2014). This notwithstanding, cancer cells maintain a $\mathrm{pH}_{\mathrm{i}}$ that is equal to or even sometimes more alkaline than their normal counterparts, implying that they upregulate net acid extrusion (see Webb et al., 2011; Boedtkjer et al., 2012; Parks et al., 2013; Pedersen and Stock, 2013). This could, in principle, happen by upregulation of the expression and/or activity of acid extruders or, conversely, by downregulation of the expression and/or activity of acid loading transporters-or by some combination thereof, and as will be described below, there is indeed evidence for both in the literature.

Plasma membrane transporters are highly interesting as biomarkers and treatment targets in cancer, given their localization at the cell surface, which renders them easily accessible for e.g., immune-based therapies. Furthermore, acid-base membrane transporters may represent an Achilles' heel for many types of cancers, which due to their high metabolic rates are predicted to be more vulnerable to inhibition of acid extrusion than normal cells. To date, however, only a few acid-base transporters have received attention as potential culprits in the altered acid extrusion pattern in cancer cells. These are the $\mathrm{Na}^{+} / \mathrm{H}^{+}$exchanger isoform 1, SLC9A1 (NHE1) (e.g., Reshkin et al., 2000; Lauritzen et al., 2010; Boedtkjer et al., 2013), the V-type $\mathrm{H}^{+}$ATPases (Sennoune et al., 2004; You et al., 2009; De Milito et al., 2010), the monocarboxylate transporter family lactate-proton transporters (MCTs, Sonveaux et al., 2008; Halestrap, 2013), and, in a very few cases, $\mathrm{HCO}_{3}^{-}$-coupled transporters (Ahmed et al., 2009; Lauritzen et al., 2010; Chen et al., 2012; Boedtkjer et al., 2013); see (Parks et al., 2013). With respect to the latter, the best studied in the 
context of cancer are the electroneutral $\mathrm{Na}^{+}, \mathrm{HCO}_{3}^{-}$cotransporter, SLC4A7 (NBCn1) and the $\mathrm{Cl}^{-} / \mathrm{HCO}_{3}^{-}$exchanger Downregulated in Adenoma (SLC26A3, DRA): NBCn1 is upregulated in breast cancer and single-nucleotide polymorphisms (SNPs) in SLC4A7 have been linked to increased breast cancer risk while DRA, as the name implies, is essentially lost early upon transformation in many colorectal cancers, and is thought to function as a tumor suppressor.

The aim of this review is to summarize current knowledge on $\mathrm{HCO}_{3}^{-}$transport in cancer, and to present and critically discuss evidence regarding the involvement of altered $\mathrm{HCO}_{3}^{-}$transporter expression and/or regulation in various cancers. We will first provide an overview of the existing evidence regarding the involvement of the SLC4 (The SLC4 family in cancer-published studies) and SLC26 (The SLC26 family and cancer-published studies) families of $\mathrm{HCO}_{3}^{-}$transporters in various cancers. Because of the wealth of information available on these two transporters compared to the rest of the family members, SLC4A7 and SLC26A3 will be discussed separately in the sections SLC4A7 (NBCn1) and Down-Regulated in Adenoma (SLC26A3, DRA), respectively. Finally, in the section Novel Candidates: Other $\mathrm{HCO}_{3}^{-}$Transport Proteins with Altered Expression in Cancer, we will explore the expression profiles of the $\mathrm{HCO}_{3}^{-}$transporting SLC4 and SLC26 family members in various cancers, using publically available databases, to set the scene for future studies on the regulation and roles of $\mathrm{HCO}_{3}^{-}$transport in cancer. Based on the published studies and our new datamining analyses presented here, we hypothesize that $\mathrm{HCO}_{3}^{-}$transporter dysregulation may have both diagnostic and therapeutic potential in cancer treatment.

\section{THE SLC4 FAMILY IN CANCER-PUBLISHED STUDIES}

The SLC4 family comprises 10 genes, of which at least 8 mediate transport of $\mathrm{HCO}_{3}^{-}$(or related molecules, such as $\mathrm{CO}_{3}^{2-}$ ) across the plasma membrane (Figure 1). SLC4 family transporters play central roles in $\mathrm{pH}$ homeostasis in a wide array of cell types (see Parker and Boron, 2013; Romero et al., 2013). Detailed accounts of the SLC4 family substrates, localization, physiological functions and other pertinent properties can be found elsewhere (see Parker and Boron, 2013; Romero et al., 2013) and will not be provided here. Importantly, however, SLC4A1-3 (frequently denoted anion exchanger (AE) 1-3) are $\mathrm{Cl}^{-} / \mathrm{HCO}_{3}^{-}$ exchangers, and at the intra- and extracellular ion concentrations and membrane potential prevalent in most cell types under normal conditions, these proteins will function as cellular acid loaders. Conversely, SLC4A4 (NBCe1), -4A5 (NBCe2), -4A7 (NBCn1), $-4 \mathrm{~A} 8$ (NDCBE), and $-4 \mathrm{~A} 10$ (NCBE/NBCn2) are $\mathrm{Na}^{+}$-coupled $\mathrm{HCO}_{3}^{-}$transporters, which are predicted to function as cellular acid extruders under the conditions prevalent in most normal cell types. Exceptions are SLC4A4 in the kidney and SLC4A5 in the choroid plexus, which are predicted to have a $1 \mathrm{Na}^{+}: 3 \mathrm{HCO}_{3}^{-}$stoichiometry and serve as acid loaders (Millar and Brown, 2008; Romero et al., 2013). It may be noted that the sometimes very acidic extracellular $\mathrm{pH}\left(\mathrm{pH}_{e}\right)$ and consequent low extracellular $\mathrm{HCO}_{3}^{-}$concentrations in tumors will diminish the driving force for $\mathrm{HCO}_{3}^{-}$import, and could in extreme cases render some of the "acid extruders" net acid importers in the tumor setting. Assuming $150 \mathrm{mM} \mathrm{Na}_{o}^{+}, 15 \mathrm{mM} \mathrm{Na}_{i}^{+}$, and $12 \mathrm{mM}$ $\mathrm{HCO}_{3}^{-}{ }_{i}\left(\mathrm{pH}_{i} \sim 7.1\right)$, the $1 \mathrm{Na}^{+}: 1 \mathrm{HCO}_{3}^{-}$cotransporters will have an inwardly directed driving force until $\mathrm{pH}_{e}$ values as low as 6.1, whereas $1 \mathrm{Na}^{+}: 2 \mathrm{HCO}_{3}^{-}$cotransporters will reverse at much more modest extracellular acidifications.

As noted above, the great majority of studies of $\mathrm{pH}_{\mathrm{i}}$ dysregulation in cancer have focused on the $\mathrm{Na}^{+} / \mathrm{H}^{+}$exchanger NHE1, MCT family transporters, and V-type ATPases. Interestingly however, in recent years, several SLC4 family members have been reported to be associated with cancer (Table 1). As mentioned, the most widely studied of these is SLC4A7 (NBCn1), which has been shown to be upregulated in human breast cancer (Boedtkjer et al., 2013) as well as in cell culture by the ErbB2/HER2 oncogene (Lauritzen et al., 2010, 2012; Gorbatenko et al., 2014), which is upregulated in up to a third of human mammary carcinomas and correlates with poor prognosis, and a SNP in which has been linked to increased risk of breast cancer [see section SLC4A7 (NBCn1), Ahmed et al., 2009; Long et al., 2010; Han et al., 2011; Sueta et al., 2012].

Dysregulation of several other members of the SLC4 family has been linked to cancer development (Table 1). An interesting series of studies relate the $\mathrm{Cl}^{-} / \mathrm{HCO}_{3}^{-}$exchangers SLC4A1 (AE1) and SLC4A2 (AE2) to gastrointestinal cancers. SLC4A1, which is normally only expressed at detectable protein levels in erythrocytes, was found to be markedly upregulated in gastric cancer cells and colorectal cancer (CRC) cells (Shen et al., 2007), and its expression to correlate with cancer progression (Xu et al., 2009). Interestingly, SLC4A1 was not found in the plasma membrane, but exclusively in the cytoplasm of these cells (Shen et al., 2007). The tumorigenic effect of SLC4A1 was proposed to involve a direct interaction of its C-terminal with the tumor suppressor p16 (INK4a), sequestering the latter from the nucleus, where it normally functions to inhibit cell cycle progression (Shen et al., 2007). Thus, SLC4A1 was proposed to increase gastric carcinogenesis by favoring cell proliferation, in a manner apparently independent of effects on $\mathrm{pH}_{\mathrm{i}}$ regulation (Shen et al., 2007). Knockdown of SLC4A1 reduced tumor progression in two different mouse models of gastric cancer, a xenograft model and chemical induction in conjunction with $H$. pylori (Suo et al., 2012). Interestingly, the upregulation of SLC4A1 in gastric cancer was recently found to be dependent on aberrant regulation by miR-24, which normally silences SLC4A1 protein expression by interaction with the $3^{\prime}$ untranslated region (UTR) of the gene (Wu et al., 2010).

SLC4A2 (AE2) was found to be upregulated in CRC (Song et al., 2012) and hepatocellular carcinoma (HCC) (Wu et al., 2006; Hwang et al., 2009) and similar to SLC4A1 appears to interact with p16 in the cytosol (Song et al., 2012). In CRC, AE2 expression correlated with Ki67 proliferation marker staining and with poor prognosis (Song et al., 2012). In gastric cancer, both upregulation (Wang et al., 2013) and downregulation (Yang et al., 2008) of SLC4A2 has been reported, and this was proposed to reflect that its expression is regulated by gastrin, the expression of which varies between different gastric cancers and cancer stages (Wang et al., 2013). Gastrin treatment decreased $\mathrm{pH}_{\mathrm{i}}$ of human gastric cancer cells in a manner correlating with the increased expression of SLC4A2 (Wang et al., 2013). On the other hand, in CRC, gastrin treatment appeared to decrease SLC4A2 expression, by interfering with binding of EGR1 to the AE2a1 promoter (Song et al., 2012; Wang et al., 2013). Furthermore, 


\section{A}

\section{SLC4 family}

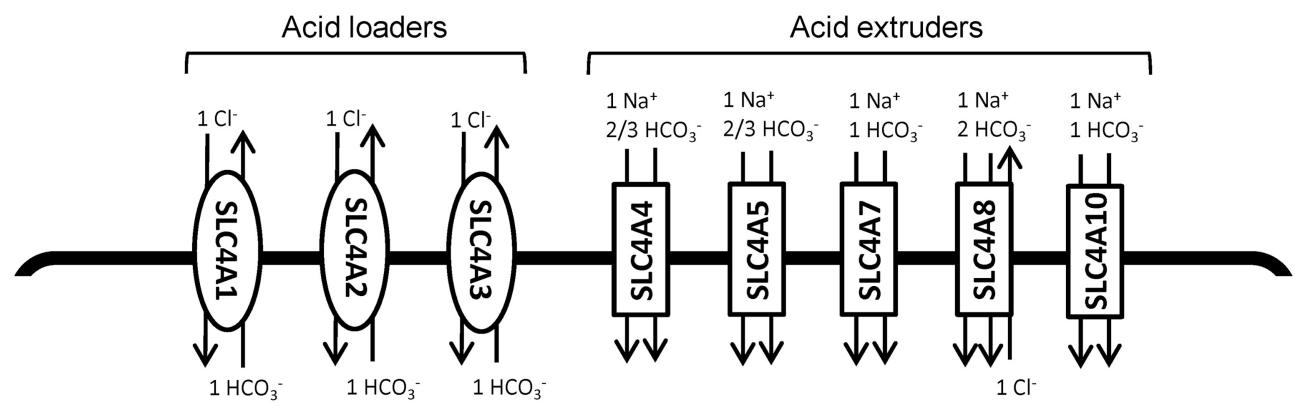

B

\section{SLC26 family}

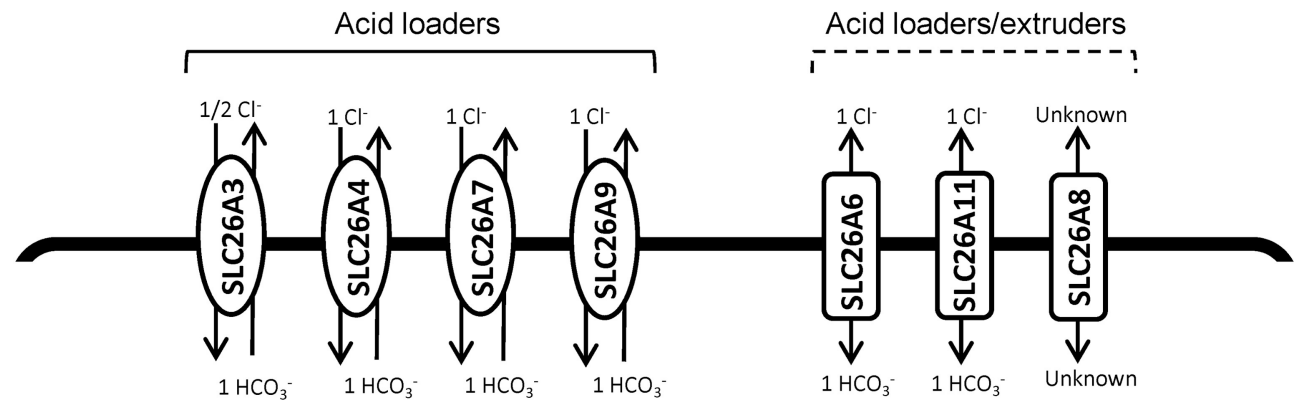

FIGURE 1 | Schematic model of $\mathrm{HCO}_{3}^{-}$transporters from the SLC4 and SLC26 family. (A) SLC4 family transporters. (B) SLC26 family transporters. In each panel, the left side shows the acid loaders and the right side shows the acid extruders. It should be noted SLC4A4 in the kidney and SLC4A5 in the choroid plexus are predicted to have a $1 \mathrm{Na}^{+}: 3 \mathrm{HCO}_{3}^{-}$stoichiometry and thus would there serve as acid loaders (Millar and Brown, 2008; Romero et al., 2013). Furthermore, SLC4A10 may additionally export $\mathrm{Cl}^{-}$; for the differing viewpoints on this, compare (Parker et al., 2008) and (Damkier et al., 2010). Other references: (Yoshitomi et al., 1985; Boron and Boulpaep, 1989; Virkki et al., 2002; Alper and Sharma, 2013; Romero et al., 2013). gastrin was found to reduce SLC4A1 expression in gastric cancer cells by eliciting its protein degradation (Tian et al., 2010). Thus, the precise regulation of SLC4A1 and -A2 in gastrointestinal cancers requires further elucidation and may be cell type specific. Moreover, whereas in contrast to SLC4A1, SLC4A2 does to some extent localize to the plasma membrane in the cancer cells (Song et al., 2012; Wang et al., 2013), it is not clear from the published studies whether the role of the exchanger in cancer progression involves both $\mathrm{pH}_{\mathrm{i}}$ regulation and $\mathrm{p} 16$ sequestration.

A SNP, rs13240966, located to an intronic region of the SLC4A2 gene, was found to be associated with reduced risk of bladder cancer, with an odds ratio for homozygotes of 0.6 (Andrew et al., 2009). On the other hand, this same SNP significantly associated with susceptibility to myelodysplastic syndromes-hematopoetic diseases that frequently become acute leukemias - in a cohort of Czech patients (Belickova et al., 2013). Impressively, homozygosity for this SNP was associated with an odds ratio of 4.86 for myelodysplastic syndromes (Belickova et al., 2013). It is to our knowledge unknown whether this intronic SNP alters the protein expression pattern of SLC4A2, and the causal link, if any, between SLC4A2 and myelodysplastic syndromes still needs to be established. It is, however, well known that transcriptional regulatory elements may be located in introns, and regulation of ion transporter expression by an intronic SNP has previously been reported (Tokuhiro et al., 2003).

Two studies of papillary thyroid cancers (PTC) in patients of Polish (Galeza-Kulik et al., 2006) and Korean (Kim et al., 2010) descent showed that mRNA expression of SLC4A4 (NBCe1) was decreased by 7- and 3-fold, respectively, in PTC compared to normal tissue. In contrast, a more recent study found SLC4A4 mRNA levels to be significantly ( 2.5 fold) upregulated in chronic myeloid leukemia (CML) stem cells compared to normal stem and progenitor cells, and was proposed as a possible target for immune-based therapy due to its cell surface localization (Gerber et al., 2013). Neither the mechanism(s) of SLC4A4 dysregulation nor the possible causal role in CML were, however, addressed in these studies. Interestingly, in a study in HT29 human CRC cells, expression of SLC4A4 was shown to be negatively regulated by miR-224 (Mencia et al., 2011). In HT29 cells with acquired resistance to methotrexate (a folate- and metabolism-targeting agent) chemotherapy, miR-224 was downregulated, resulting in upregulation of SLC4A4. Notably, siRNA-mediated knockdown of SLC4A4 resulted in increased sensitivity to methotrexate treatment, and this was reversed upon anti-miR-224 transfection (Mencia et al., 2011). 
Table 1 | Summary of the reported data on $\mathrm{HCO}_{3}^{-}$transporting SLC4 and SLC26 family transporters in cancer.

\begin{tabular}{|c|c|c|c|c|c|}
\hline Transporter & Alternative name & Cancer & Perturbation & Functional link to cancer? & References \\
\hline SLC4A2 & EPB3L1, AE2 & $\begin{array}{l}\text { Gastric, CRC, } \\
\mathrm{HCC} \text {, bladder }\end{array}$ & $\begin{array}{l}\text { Expression } \downarrow \uparrow \\
\text { SNP rs13240966 }\end{array}$ & $\begin{array}{l}\text { Poor prognosis, SNP_reduced } \\
\text { risk of bladder cancer }\end{array}$ & $\begin{array}{l}\text { Wu et al., 2006; Yang et al., } \\
\text { 2008; Andrew et al., 2009; } \\
\text { Hwang et al., 2009; Tian } \\
\text { et al., 2010; Song et al., 2012; } \\
\text { Belickova et al., 2013; Wang } \\
\text { et al., } 2013\end{array}$ \\
\hline
\end{tabular}

\begin{tabular}{lllll}
\hline SLC4A4 & NBCe1 & PTC, CML, CRC & Expression $\downarrow \uparrow$ & Resistance to methotrexate \\
\hline SLC4A7 & NBCn1 & Breast cancer & $\begin{array}{l}\text { Expression }(\downarrow) \uparrow \\
\text { SNP rs4973768 }\end{array}$ & $\begin{array}{l}\text { Unknown, SNP_associated with } \\
\text { breast cancer risk }\end{array}$
\end{tabular}

Galeza-Kulik et al., 2006; Kim et al., 2010; Mencia et al., 2011; Gerber et al., 2013

Chen et al., 2007; Ahmed et al., 2009; Lauritzen et al., 2010, 2012; Long et al., 2010; Han et al., 2011; Mulligan et al., 2011; Boedtkjer et al., 2012, 2013; Fasching et al., 2012; Sueta et al., 2012; Fernandez-Navarro et al., 2013; Gorbatenko et al., 2014;

\begin{tabular}{|c|c|c|c|c|c|}
\hline SLC26A2 & DTDST & $\mathrm{CRC}$ & Expression $\downarrow$ & $\begin{array}{l}\text { Reduced sulfation of sialyl Lewis } \\
x \text { ligand }\end{array}$ & Yusa et al., 2010 \\
\hline SLC26A3 & DRA, CLD & $\begin{array}{l}\text { CRC, Instestina, } \\
\text { breast cancer }\end{array}$ & $\begin{array}{l}\text { Expression } \downarrow \\
\text { Mutations }\end{array}$ & Reduces proliferation & $\begin{array}{l}\text { Schweinfest et al., 1993; } \\
\text { Hoglund et al., 1996; Antalis } \\
\text { et al., 1998; Hemminki et al., } \\
\text { 1998; Chapman et al., 2002; } \\
\text { Schweinfest et al., 2006; } \\
\text { Lauriola et al., 2010; Baker } \\
\text { et al., 2011; Dalerba et al., } \\
\text { 2011; Mosakhani et al., 2012; } \\
\text { de Ronde et al., } 2013\end{array}$ \\
\hline SLC26A4 & PDS, pendrin & Thyroid cancer & Expression $\downarrow$ & Unknown & $\begin{array}{l}\text { Arturi et al., 2001; Porra et al., } \\
\text { 2002; Xing et al., 2003; Iwata } \\
\text { et al., } 2011\end{array}$ \\
\hline
\end{tabular}

Arrows $(\uparrow \downarrow)$ indicate reported up- or down-regulation, respectively. See text for details. Abbreviations: EPB3, Erythrocyte Membrane Protein Band 3; AE1, Anion

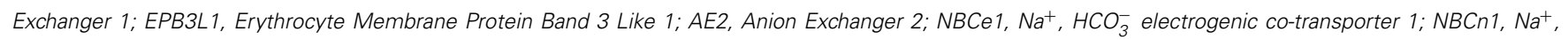
$\mathrm{HCO}_{3}^{-}$neutral co-transporter 1; DTDST, Diastrophic Dysplasia Sulfate Transporter; DRA, Down-Regulated in Adenoma; CLD, Congenital Chloride Diarrhoea; PDS, Pendred Syndrome.

\section{THE SLC26 FAMILY AND CANCER—PUBLISHED STUDIES}

The second major group of mammalian plasma membrane $\mathrm{HCO}_{3}^{-}$transporters is the SLC26 family. This family comprises 11 genes of which 8 have been shown to carry $\mathrm{HCO}_{3}^{-}$(see Alper and Sharma, 2013). All of the SLC26 members function as anion exchangers, and although the stoichiometry for these transporters is not fully elucidated, they appear to most commonly serve as cellular acid loaders (Figure 1). Three of them-SLC26A7, -9, and -11 can additionally operate as anion channels (see Alper and Sharma, 2013). Dysregulation of several members of this family has been linked to cancer development (Table 1). As noted above, one in particular has received widespread attention for its dysregulation in CRC, namely SLC26A3, also known as Downregulated in Adenoma (DRA), which was first described as a gene downregulated in CRC in 1993 (Schweinfest et al., 1993). The extensive body of evidence on the regulation and roles of SLC26A3 in cancer is discussed in the section Down-Regulated in Adenoma (SLC26A3, DRA).

A few other SLC26 family members have been linked to cancer. Expression of SLC26A2 (DTDST), an exchanger carrying $\mathrm{Cl}^{-}$, oxalate and $\mathrm{SO}_{4}^{2-}$, but not thought to transport $\mathrm{HCO}_{3}^{-}$(see Alper and Sharma, 2013), was found to be strongly reduced in CRC, 
likely due to epigenetic silencing (aberrant histone methylation and acetylation) (Yusa et al., 2010). This was assigned a role in reducing sulfation of sialyl Lewis ${ }^{x}$ and increasing proliferation in CRC (Yusa et al., 2010). SLC26A4 (Pendrin) exhibits reduced expression levels in thyroid cancers (Arturi et al., 2001; Porra et al., 2002). The possible causal role of this downregulation in cancer development is to our knowledge unknown, but given the role of SLC26A4 as an anion exchanger capable of transporting $\mathrm{Cl}^{-}, \mathrm{HCO}_{3}^{-}$, and $\mathrm{I}^{-}$, it is tempting to speculate that its downregulation may contribute to maintaining an elevated $\mathrm{pH}_{\mathrm{i}}$ in these cells. A role for $\mathrm{I}^{-}$transport is of course also conceivable, however, the SLC26A4 knockout mouse has no thyroid phenotype even under dietary iodide deficiency (Iwata et al., 2011), suggesting that this transporter is not the main $\mathrm{I}^{-}$uptake pathway in the thyroid. Interestingly, the $5^{\prime}$ region of the SLC26A4 gene was found to be hyper-methylated as an early event in the majority of malignant human thyroid tumors, presumably accounting for at least part of the decreased SLC26A4 expression in these tumors (Xing et al., 2003).

\section{FUNCTION AND EXPRESSION OF HCO ${ }_{3}^{-}$TRANSPORTERS IN CANCER}

ROLES OF THE CARBONIC BUFFER SYSTEM IN TUMOR PH REGULATION

Recent studies from several laboratories have documented the specific importance of $\mathrm{HCO}_{3}^{-}$in tumor $\mathrm{pH}$ regulation. Intriguingly, it was demonstrated that oral administration of $\mathrm{HCO}_{3}^{-}$could inhibit tumor metastasis in prostate-, breast- and colon cancer cell line derived tumors. This apparently occurred by reducing the extracellular acidity of the highly acid-extruding tumors, in absence of changes in the $\mathrm{pH}$ of blood or normal tissues (Robey et al., 2009; Silva et al., 2009; Wojtkowiak et al., 2011; Estrella et al., 2013). Furthermore, early administration of $\mathrm{HCO}_{3}^{-}$prevented carcinogenesis in Transgenic Adenocarcinoma of the Mouse Prostate (TRAMP) mice, a model of prostate cancer (Ibrahim-Hashim et al., 2012). Although the mechanisms underlying these effects are not absolutely clear, the authors suggest that increased tumor $\mathrm{pH}_{e}$ inhibits the activity of extracellular proteases, such as Cathepsin B, in turn reducing invasiveness (Robey et al., 2009). This hypothesis was recently supported by the finding that in vivo matrix metalloproteinase and cathepsin activities, estimated by fluorescent reporters, are reduced in xenograft tumors following $\mathrm{NaHCO}_{3}$ ingestion (Robey and Nesbit, 2013). A recent study, however, points to the drawbacks and the possible side effects of chronic $\mathrm{HCO}_{3}^{-}$administration such as metabolic alkalosis and additionally suggests combinational therapy targeting proton production with dichloroacetate (DCA) (Martin et al., 2012).

The importance of the carbonic buffer system in cancer is also underscored by the ability of the hypoxia inducible carbonic anhydrase IX (CAIX), which is upregulated in a wide variety of cancers (Bartosova et al., 2002; Chen et al., 2005; Supuran, 2008; Perez-Sayans et al., 2012), to increase $\mathrm{HCO}_{3}^{-}$-dependent resting $\mathrm{pH}_{\mathrm{i}}$ and decrease $\mathrm{pH}_{e}$ in Chinese hamster lung CCL39 fibroblasts. CAIX knockdown has also been shown to reduce growth of xenografts of LS174Tr colon cancer cells in nude mice (Chiche et al., 2009). While most of the work on carbonic anhydrases in cancer has focused on CAIX as a biomarker, studies from several groups have highlighted the importance of the carbonic buffer system for $\mathrm{pH}$ regulation in various cancer cell lines under normal, acidic, and hypoxic growth conditions When cancer cell lines from pancreas, breast, and colon were grown in 2D culture, the mechanism of net acid extrusion after an imposed acid load varied between cell lines, from mainly $\mathrm{HCO}_{3}^{-}$influx to mainly $\mathrm{H}^{+}$efflux (Hulikova et al., 2011). Notably, at a $\mathrm{pH}_{e}$ of 7.4, the $\mathrm{HCO}_{3}^{-}$flux was rather similar between cell lines, whereas the $\mathrm{H}^{+}$efflux varied substantially (Hulikova et al., 2011). The ability to recover from an imposed acid load was reduced by decreasing $\mathrm{pH}_{e}$. This decrease could be mostly ascribed to reduced $\mathrm{H}^{+}$ efflux, whereas the $\mathrm{HCO}_{3}^{-}$influx was less affected by acidic $\mathrm{pH}_{e}$ (Hulikova et al., 2011). A similar pattern was observed after exposing cancer cell lines to hypoxia, which reduced SLC9A1mediated $\mathrm{H}^{+}$flux, whereas $\mathrm{HCO}_{3}^{-}$flux was hypoxia-insensitive (Hulikova et al., 2013). Collectively, these studies suggest that $\mathrm{HCO}_{3}^{-}$transport may serve a rather stable "housekeeping" role in these cell lines, whereas $\mathrm{H}^{+}$transport is highly variable and attenuated under conditions of extracellular acidification and hypoxia. As these conditions are prevalent in solid tumors (Vaupel et al., 1981; Vaupel, 2004), the authors next addressed the mechanisms of $\mathrm{pH}_{\mathrm{i}}$ regulation in multicellular spheroids mimicking the tumor 3D structure. These studies demonstrated that inhibition of $\mathrm{HCO}_{3}^{-}$transport by 4,4'-diisothiocyanatostilbene-2,2' disulfonic acid (DIDS) generally lead to a non-uniform decrease in the rate of $\mathrm{pH}_{\mathrm{i}}$ recovery after acid loading, with the greatest effect of DIDS observed in the core of spheroids. Importantly, the authors provide evidence that the carbonic buffer system plays a dual role, supplying $\mathrm{HCO}_{3}^{-}$as substrate for transport and providing a mobile buffer facilitating the transport of the otherwise poorly mobile $\mathrm{H}^{+}$ions away from the cells. Thus, in MDA-MB468 breast cancer spheroids, which rely mainly on $\mathrm{H}^{+}$transport for $\mathrm{pH}_{\mathrm{i}}$ recovery, substitution of $\mathrm{HCO}_{3}^{-}$with $25 \mathrm{mM}$ HEPES had no effect on the ability to recover from an acid load. However, decreasing the concentration of HEPES elicited a non-uniform pattern of $\mathrm{pH}_{\mathrm{i}}$ recovery with the slowest recovery at the core of the spheroid consistent with $\mathrm{CO}_{2} / \mathrm{HCO}_{3}^{-}$(and under experimental conditions HEPES) serving as a mobile buffer important for $\mathrm{pH}_{\mathrm{i}}$ recovery under 3D conditions (Hulikova et al., 2011). Moreover, the findings predict that because of the inhibitory effects of extracellular acidification and hypoxia on SLC9A1, $\mathrm{HCO}_{3}^{-}$transport will be progressively more important with distance from functional blood vessels in the tumor. Finally, inhibition of either SLC9A1 or $\mathrm{HCO}_{3}^{-}$transport attenuated spheroid growth, suggesting that both types of transporters are important for cancer cell survival and/or proliferation under 3D conditions (Hulikova et al., 2011).

As mentioned above, the strongest evidence for involvement of $\mathrm{HCO}_{3}^{-}$transporters in human cancer has been provided for NBCn1 (SLC4A7) and DRA (SLC26A3). The current evidence linking these two transport proteins to cancer will be addressed below.

\section{SLC4A7 (NBCn1)}

The first link between this protein and breast cancer was provided when SLC4A7 was reported to be a tyrosine kinase substrate in MCF10AT breast cancer cells and to be expressed at reduced 
levels in human breast cancer samples compared to matched normal breast tissue in a population of Asian women (Chen et al., 2007). However, in the MCF10AT progression model, SLC4A7 expression was approximately three times higher in low- and intermediate-grade lesions than in normal cells (Chen et al., 2007) suggesting that at least early in breast cancer development, SLC4A7 expression may be upregulated. The potential importance of these observations was supported when multiple genome-wide association studies (GWAS) subsequently showed that a SNP in the SLC4A7 gene was linked to breast cancer: independent GWAS covering women of European (Ahmed et al., 2009), Korean (Han et al., 2011), Chinese (Long et al., 2010), and Japanese (Sueta et al., 2012) descent showed that the rs4973768 SNP corresponding to the $3^{\prime}$-UTR of SLC4A7 is associated with breast cancer with odds ratios for homozygosity between 1.2 and 1.3. The rs4973768 SNP has an allele frequency between 15 and $50 \%$ across the range of investigated ethnicities (Ahmed et al., 2009; Long et al., 2010; Han et al., 2011; Sueta et al., 2012) and thus could play a substantial role for human breast cancer development. In carriers of the cancer susceptibility gene BRCA2, the SNP was significantly associated with estrogen receptor (ER)positive, but not with ER-negative disease (Mulligan et al., 2011). This suggests a possible link to ER signaling, which may also underlie the apparent dependence of the breast cancer association of this SNP on pre- or post-menopausal status (Chen et al., 2012; Fernandez-Navarro et al., 2013).

Although it has been noted that the rs4973768 SNP may alter the binding affinity of a microRNA binding site (Boedtkjer et al., 2012) and thus alter SLC4A7 mRNA stability and translation, the consequences of the rs4973768 SNP for SLC4A7 expression and function have not yet been experimentally determined. Of note, the rs4973768 SNP did not link to breast cancer survival in a large GWAS study of 25853 breast cancer patients with available followup data (Fasching et al., 2012). Moreover, there was no association between rs4973768 and mammographic density—a risk factor for breast cancer-except in a subgroup of pre-menopausal women (Fernandez-Navarro et al., 2013).

Human breast cancer is a fairly heterogeneous disease, which differs among others in expression levels for hormone (e.g., estrogen and progesterone) and growth factor (e.g., ErbB2) receptors. The receptor status of the breast carcinomas modifies prognosis. In particular, expression of a constitutively active, $\mathrm{NH}_{2}$-truncated ErbB2 $(\triangle$ NErbB2) receptor has been widely shown to confer poor prognosis and limit treatment options (Christianson et al., 1998). In this light, it is interesting that heterologous expression of the $\triangle \mathrm{NErbB} 2$ receptor in human MCF-7 breast cancer cells enhances expression of SLC4A7 and cellular acid extrusion activity (Lauritzen et al., 2010).

Recent studies from our group demonstrated that $\triangle$ NErbB2dependent SLC4A7 upregulation is controlled via Akt-, ERKand Src-dependent pathways (Gorbatenko et al., 2014; Figure 2). Inhibition or siRNA-mediated knockdown of these kinases decreased SLCAA7 mRNA and protein levels. Furthermore, the SLC4A7 promoter was characterized in detail. Although SLC4A7 was suggested to have several alternative promoters, all epigenetic marks, correlating with presence of actively transcribed chromatin, such as $\mathrm{H} 3 \mathrm{~K} 27 \mathrm{Ac}$ and $\mathrm{H} 3 \mathrm{~K} 27 \mathrm{me} 3$, were only detectible near the first possible SLC4A7 exon. The SLC4A7 core promoter is TATA-box-less, yet contains a large GC rich region. Despite the fact that $\mathrm{CpG}$ island containing promoters usually exhibit broad transcription initiation, Cap Analysis of Gene Expression (CAGE) data from MCF-7 breast cancer cells suggested a single basefocused transcription start site (TSS) and the sequence around it perfectly resembled an initiator (Inr) element (Gorbatenko et al., 2014). Luciferase reporter assays of the putative SLC4A7 promoter region demonstrated that mutation of the Inr element led to $50 \%$ loss of promoter activity (Figure 2). $\triangle$ NErbB2 signaling stimulated the promoter activity by $\sim 2.5$ fold and further deletions identified the minimal, $\triangle$ NErbB2 sensitive region within the promoter. Two related transcription factors with known roles in cancer, Sp1 and KLF4, bind to the SLC4A7 promoter, exerting opposite functions: $\mathrm{Sp} 1$ represses and KLF4 activates SLC4A7 transcription (Gorbatenko et al., 2014). Notably, KLF4dependent transcription was stimulated by $\triangle \mathrm{NErbB} 2$ signaling and this was at least partially controlled by Akt1 and ERK1 kinases (Figure 2). Finally, stimulation of full-length ErbB2 receptors in SKBr3 breast cancer cells increased both SLC4A7 expression and $\mathrm{HCO}_{3}^{-}$-dependent $\mathrm{pH}_{i}$ recovery (Gorbatenko et al., 2014).

Although the initial investigations in a population of Asian women suggested that the expression levels for SLC4A7 are reduced in breast cancer tissue compared to normal breast tissue (Chen et al., 2007), this has not subsequently been confirmed. In contrast, based on tissue samples from women of European descent, we recently showed that the plasma membrane expression of SLC4A7 is upregulated in human primary breast carcinomas and metastases compared to matched normal breast tissue (Boedtkjer et al., 2013). We furthermore showed that $\mathrm{Na}^{+}, \mathrm{HCO}_{3}^{-}$cotransport of low sensitivity to DIDS, a hallmark of epithelial SLC4A7-mediated $\mathrm{HCO}_{3}^{-}$transport, (Parker and Boron, 2013) is the predominant mechanism of acid extrusion in freshly isolated slices of human primary breast carcinomas (Boedtkjer et al., 2013). Interestingly, only 10-20\% of the investigated human breast carcinomas in our study showed upregulation or gene amplification of the ErbB2 receptor, suggesting that upregulated SLC4A7 expression is of general importance in breast cancer and not restricted to cancers characterized by increased ErbB2 signaling (Boedtkjer et al., 2013). The enhanced expression of SLC4A7 and its putative role in cellular acid extrusion would imply that SLC4A7 is involved in establishing the characteristically high $\mathrm{pH}_{\mathrm{i}}$ and low $\mathrm{pH}_{e}$ observed in breast carcinomas. In congruence, steady-state $\mathrm{pH}_{\mathrm{i}}$ in slices of human primary breast carcinomas decreased around 0.35 units upon omission of $\mathrm{CO}_{2} / \mathrm{HCO}_{3}^{-}$(Boedtkjer et al., 2013).

\section{RELATIVE ROLES OF SLC4A7 (NBCn1) AND SLC9A1 (NHE1) IN CANCER}

In most cell systems, $\mathrm{Na}^{+}, \mathrm{HCO}_{3}^{-}$cotransport acts in parallel with $\mathrm{Na}^{+} / \mathrm{H}^{+}$exchange to extrude intracellular acid loads, and a brief discussion of their relative roles in cancer is therefore warranted. Multiple studies have demonstrated that $\mathrm{Na}^{+} / \mathrm{H}^{+}$ exchange plays a significant role in cancer cells (Reshkin et al., 2013) and xenograft studies have shown that $\mathrm{Na}^{+} / \mathrm{H}^{+}$exchange deficiency inhibits tumor growth of MGH-U1 bladder carcinoma 


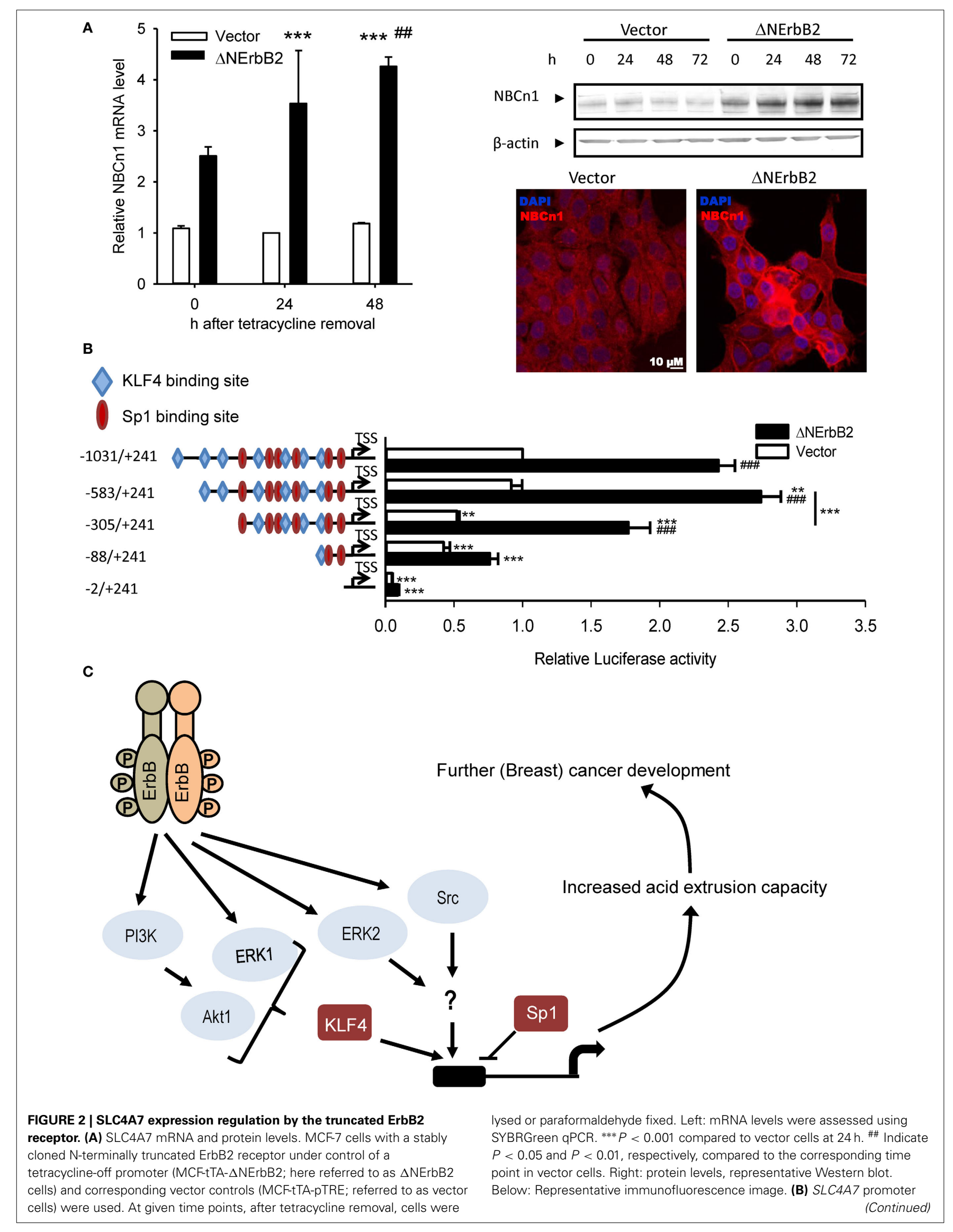




\section{FIGURE 2 | Continued}

activity and regulation by ErbB2. Cells were co-transfected with the pGL3 basic vector, in which the relevant DNA constructs were cloned upstream of the firefly luciferase gene. Promoter activity was assessed by dual luciferase assays. At $24 \mathrm{~h}$ after tetracycline removal to induce $\triangle \mathrm{NErbB2}$ expression, cells were transfected with the indicated constructs and with the PHRG-B vector carrying Renilla luciferase, and luciferase activity was measured another $24 \mathrm{~h}$ later. Data are shown as firefly luciferase activity normalized to Renilla luciferase activity, relative to that in vector cells. Numbers indicate sequence length; - and + indicate sequence position up- or down-stream, respectively, of the TSS obtained from CAGE data. Blue rhombuses and red circles indicate binding sites for KLF4 and Sp1, respectively. Only binding sites with relative profile score threshold $>90 \%$ of Jaspar position weight matrices (PWMs) are depicted. Data are from 3 to 6 independent experiments/conditions.

${ }^{* *} P<0.01,{ }^{* * *} P<0.001$ vs. full-length sequence in same cell type unless indicated with a line; ${ }^{\# \#} P<0.001$ vs. other cell type in same conditions. (C) Model of ErbB2 dependent SLC4A7 expression regulation. See text for details. Data in (A) are from Lauritzen et al. (2010), except immunofluorescence data, which are unpublished data by C.W. Olesen. Data in (B) and the model in (C) are redrawn with permission, from Gorbatenko et al. (2014). cells (Rotin et al., 1989). SLC9A1 has been shown to contribute to $\mathrm{pH}_{\mathrm{i}}$ regulation in cultured MCF-7 cells (Lauritzen et al., 2010) and human breast cancer slices (Boedtkjer et al., 2013). In MCF-7 cells, no significant change in SLC9A1 expression was observed in response to heterologous expression of $\triangle N E r b B 2$, yet the contribution of SLC9A1 to cellular acid extrusion was substantial (Lauritzen et al., 2010) and $\triangle$ NErbB2 expression was associated with increased phosphorylation of SLC9A1 at Ser703 (Lauritzen et al., 2012), which has previously been shown to increase SLC9A1 activity (Takahashi et al., 1999). In the human breast cancer slices, $\mathrm{Na}^{+} / \mathrm{H}^{+}$exchange contributed to net acid extrusion primarily at low $\mathrm{pH}_{\mathrm{i}}$ values (Boedtkjer et al., 2013). Although the role of $\mathrm{Na}^{+} / \mathrm{H}^{+}$exchange may be less obvious than the role of $\mathrm{Na}^{+}, \mathrm{HCO}_{3}^{-}$cotransport for cellular net acid extrusion and global steady-state $\mathrm{pH}_{\mathrm{i}}$ control in breast carcinomas (Boedtkjer et al., 2013), cell culture experiments have clearly demonstrated that SLC9A1 plays a prominent and specific role for modulating cell migration, survival, growth and proliferation (Stock and Schwab, 2006; Schwab et al., 2012). These effects may in part be explained by changes in $\mathrm{pH}$ in local restricted compartments (Ro and Carson, 2004) or may be due to transport-independent interactions with intra- or extracellular structural components or with cellular signaling cascades (Stock and Schwab, 2006). Initial studies to explore whether SLC4A7 plays a similar role for cell migration have been conducted using pharmacological inhibitors of $\mathrm{Na}^{+} / \mathrm{H}^{+}$exchange (5-(N-ethyl-N-isopropyl) amiloride, EIPA) and $\mathrm{Na}^{+}, \mathrm{HCO}_{3}^{-}$ cotransport (S0859) in $\triangle \mathrm{NErbB2}$-expressing MCF-7 breast cancer cells: EIPA was surprisingly shown to enhance cell migration while S0859 had no effect (Lauritzen et al., 2012). An earlier study suggested that the electrogenic $\mathrm{Na}^{+}, \mathrm{HCO}_{3}^{-}$cotransporter NBCel had a minor stimulatory role on migration in transformed $\mathrm{Na}^{+} / \mathrm{H}^{+}$exchange deficient Madin-Darby Canine Kidney (MDCK) cells (Schwab et al., 2005), providing evidence that $\mathrm{Na}^{+}$, $\mathrm{HCO}_{3}^{-}$cotransport can modulate cell motility at least in some cell systems.

Since SLC4A7 is also expressed in the smooth muscle and endothelial cells of the vascular wall (Boedtkjer et al., 2008) and is important for maintaining vasomotor responsiveness (Boedtkjer et al., 2011) and possibly arterial structure (Boedtkjer and Aalkjaer, 2013), it is conceivable that SLC4A7 may also in part affect cancer development by modifying blood perfusion of tumors. Efficient acid extrusion mechanisms in the vascular smooth muscle cells and endothelial cells of tumor vessels would be expected to be particularly important due to the high local acid load.

\section{DOWN-REGULATED IN ADENOMA (SLC26A3, DRA)}

SLC26A3 was first described based on its reduced expression levels in colorectal adenomas and adenocarcinomas compared to normal colon epithelium (Schweinfest et al., 1993). Subsequently, SLC26A3 was reported to function as a $\mathrm{Cl}^{-}$/anion exchanger in the luminal membrane of the gastrointestinal tract and was proposed to contribute to transepithelial $\mathrm{HCO}_{3}^{-}$secretion (Jacob et al., 2002). The anions transported by SLC26A3 appear to include $\mathrm{Cl}^{-}, \mathrm{HCO}_{3}^{-}$and $\mathrm{SO}_{4}^{2-}$ while transport of oxalate is limited (Jacob et al., 2002). Since SLC26A3 can remove $\mathrm{HCO}_{3}^{-}$from cells, it is possible that lower expression of SLC26A3 reduces the net acid load on the cells and eases the elimination of acidic waste products produced by cancer cell metabolism. The role of SLC26A3 for $\mathrm{pH}_{\mathrm{i}}$ regulation in colon carcinomas, however, needs further investigation.

Mutation of SLC26A3 - in addition to causing congenital chloride diarrhea (Hoglund et al., 1996)_increases the risk of intestinal cancer (Hemminki et al., 1998). It is not clear at this point, however, whether the correlation between SLC26A3 and colon cancer is due to its role in $\mathrm{HCO}_{3}^{-}$transport (and hence to regulation of $\mathrm{pH}_{\mathrm{i}}$ and local $\mathrm{pH}_{e}$ ), a role in cellular $\mathrm{Cl}^{-}$homeostasis, or other less understood functions. Interestingly, mutations in the $\mathrm{Cl}^{-}$channel Cystic Fibrosis Transmembrane conductance Regulator (CFTR), which is expressed in the luminal membrane of colonic crypt cells (Crawford et al., 1991), have also been suggested to be inversely associated with colon cancer (Padua et al., 1997), supporting the possibility for $\mathrm{Cl}^{-}$-dependent effects of SLC26A3. SLC26A3 has, furthermore, been proposed to modify cellular growth: heterologous expression of SLC26A3 induces growth suppression in various cancer cell lines (Chapman et al., 2002) while SLC26A3 knockout mice display altered morphology of the colonic mucosa with an expanded proliferative zone (Schweinfest et al., 2006). In combination, these findings suggest multiple possible roles of SLC26A3 in cancer development, and additional experimental investigations are required to further our mechanistic understanding. Notably, however, SLC26A3 expression, together with expression of three other genes, had predictive value for survival in patients with CRC of the wild type KRAS type (Baker et al., 2011).

SLC26A3 downregulation correlates with colon tumor progression (Antalis et al., 1998); and in congruence with this, expression levels for SLC26A3 have been reported to be controlled by miR-31, which is upregulated in tumors from patients with progressive CRC compared to patients with disease control (Mosakhani et al., 2012). Although SLC26A3 has been shown to be a prognostic marker in colon cancer (Dalerba 
et al., 2011), a potential causative role of SLC26A3 expression in colon carcinogenesis is still controversial: some investigators have shown that SLC26A3 expression correlates with cell differentiation, i.e., expression of SLC26A3 occurs preferentially in highly differentiated colonic epithelial cells but is low in dedifferentiated cells (Hoglund et al., 1996). The association between SLC26A3 expression levels and cellular differentiation in the normal epithelium, however, does not appear to be recapitulated in tumors since SLC26A3 expression has been shown to be reduced in both differentiated and dedifferentiated tumors (Antalis et al., 1998). Since cancer cells are generally dedifferentiated compared to normal epithelial cells, however, it cannot currently be excluded that reduced expression of SLC26A3 in colorectal adenocarcinomas is a consequence of the dedifferentiated state rather than a mechanistic cause of malignant development.

Since SLC26A3 is expressed in colonic epithelium but not in blood cells, detection of circulating tumor cells by identification of SLC26A3 mRNA was suggested as a screening method for CRC, but the specificity has so far been too low for SLC26A3 to qualify as a clinically useful marker (Lauriola et al., 2010).

It is currently unclear from the literature whether SLC26A3 is also of relevance to other types of cancer (see, however, the section Novel Candidates: Other $\mathrm{HCO}_{3}^{-}$Transport Proteins with Altered Expression in Cancer); but consistent with more general implications, SLC26A3 was recently shown to be a marker of resistance to neoadjuvant chemotherapy in ErbB2 receptor negative breast cancer (de Ronde et al., 2013).

\section{NOVEL CANDIDATES: OTHER $\mathrm{HCO}_{3}^{-}$TRANSPORT PROTEINS WITH ALTERED EXPRESSION IN CANCER}

In the previous sections, we have discussed the published literature on $\mathrm{HCO}_{3}^{-}$transporters in relation to cancer. As evident from this, only a few studies directly addressing this issue are yet available, and for most $\mathrm{HCO}_{3}^{-}$transporters, their possible relation to cancer development is completely uninvestigated. In order to identify novel potential candidates for dysregulation of $\mathrm{HCO}_{3}^{-}$transport in cancer, we have mined two authoritative bioinformatics sources: The Catalog of Somatic Mutations in Cancer (COSMIC) database of cancer-associated mutations (http://cancer.sanger.ac.uk, Forbes et al., 2011) and The Cancer Genome Atlas (TCGA, http://cancergenome.nih. gov/), the latter using the Cancer Genomics Browser (https:// genome-cancer.ucsc.edu/, Zhu et al., 2009; Goldman et al., 2013).

Table 2 summarizes mutation rates for SLC4 and SLC26 members extracted from COSMIC. As seen, the mutation rates for the SLC4 and SLC26 families vary markedly between the five different cancer types shown. Less than $1 \%$ of the genes from these two families exhibit somatic mutations in breast and pancreatic cancer. In contrast, in endometrial cancers, the mutation rate is $5 \%$ or higher for almost all of the SLC4 and SLC26 genes. This should be seen in the light of the generally high frequency of genomic instability in endometrial cancers (MatiasGuiu and Prat, 2013), however, it would be highly interesting to assess whether any of these mutations alter transporter function. In colon and lung cancer, the mutation rates are very different between the different genes, but it is interesting to note
Table 2 | Somatic mutation rates for SLC4 and SLC26 family transporters in different cancer types.

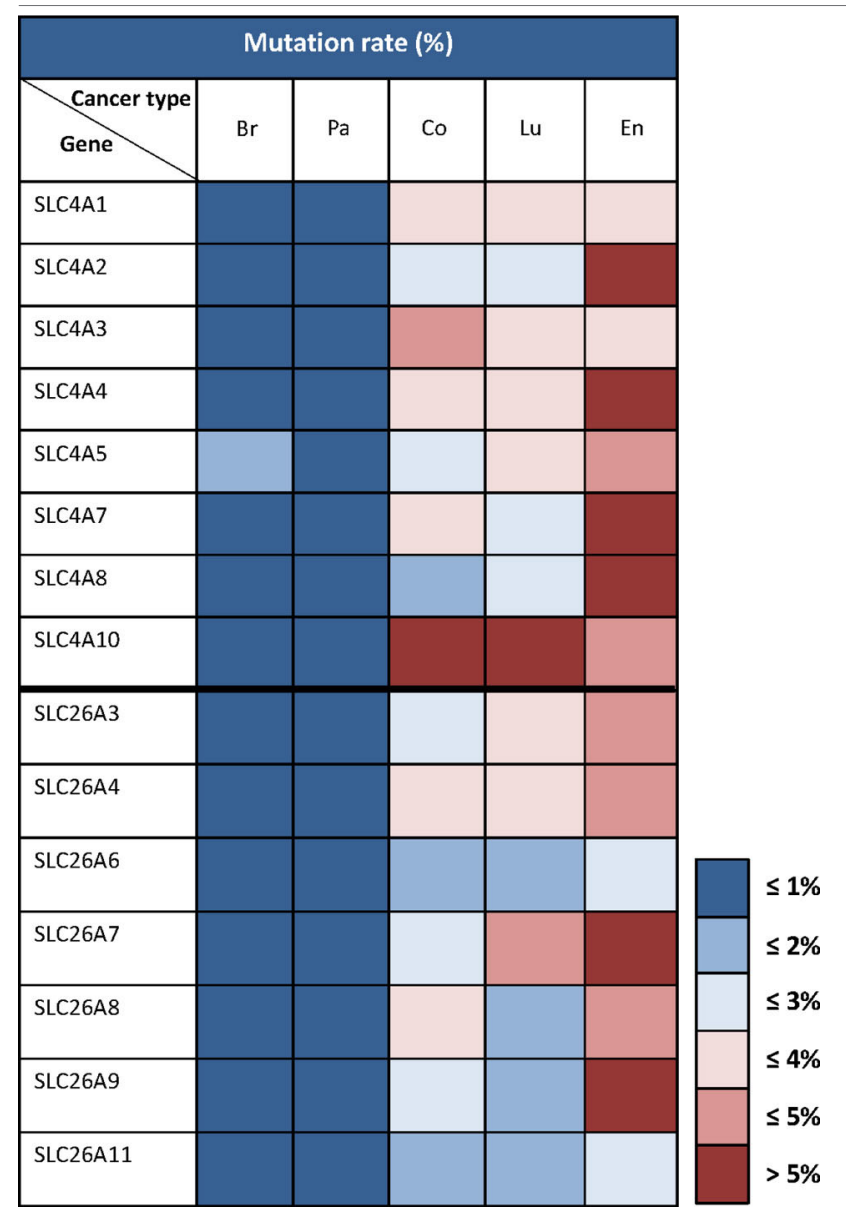

Data are obtained from the COSMIC cancer mutation database. See text for details.

that overall, the SLC4 family has a higher mutation rate compared to the SLC26 family in these two cancer types. These data, while preliminary, suggest that mutations in $\mathrm{HCO}_{3}^{-}$transporters could be present in multiple cancers and it would be interesting to address in future studies whether specific mutations with effects on transporter function might contribute to the cancer phenotype.

Figures 3-5 illustrate results from TGCA datasets on the mRNA expression profiles of SLC4 and SLC26 members (excluding those known not to carry $\mathrm{HCO}_{3}^{-}$) and selected carbonic anhydrases (CAII, CAIX, and CAXII) in breast- (Figure 3), colon(Figure 4), and lung cancer (Figure 5), respectively.

As seen in Figure 3, firstly, the mRNA expression levels of most of the SLC4 and SLC26 family members differ widely between normal and cancer tissue, with a clear trend toward upregulation of SLC4A3, SLC4A7, and SLC26A6, and downregulation of SLC4A1 in cancer compared to normal tissue. Second, the two major subtypes of lung cancer (squamous cell carcinoma and adenocarcinoma) differ markedly in expression of the two families of transporters. For example, SLC4A4, SLC4A8, and 


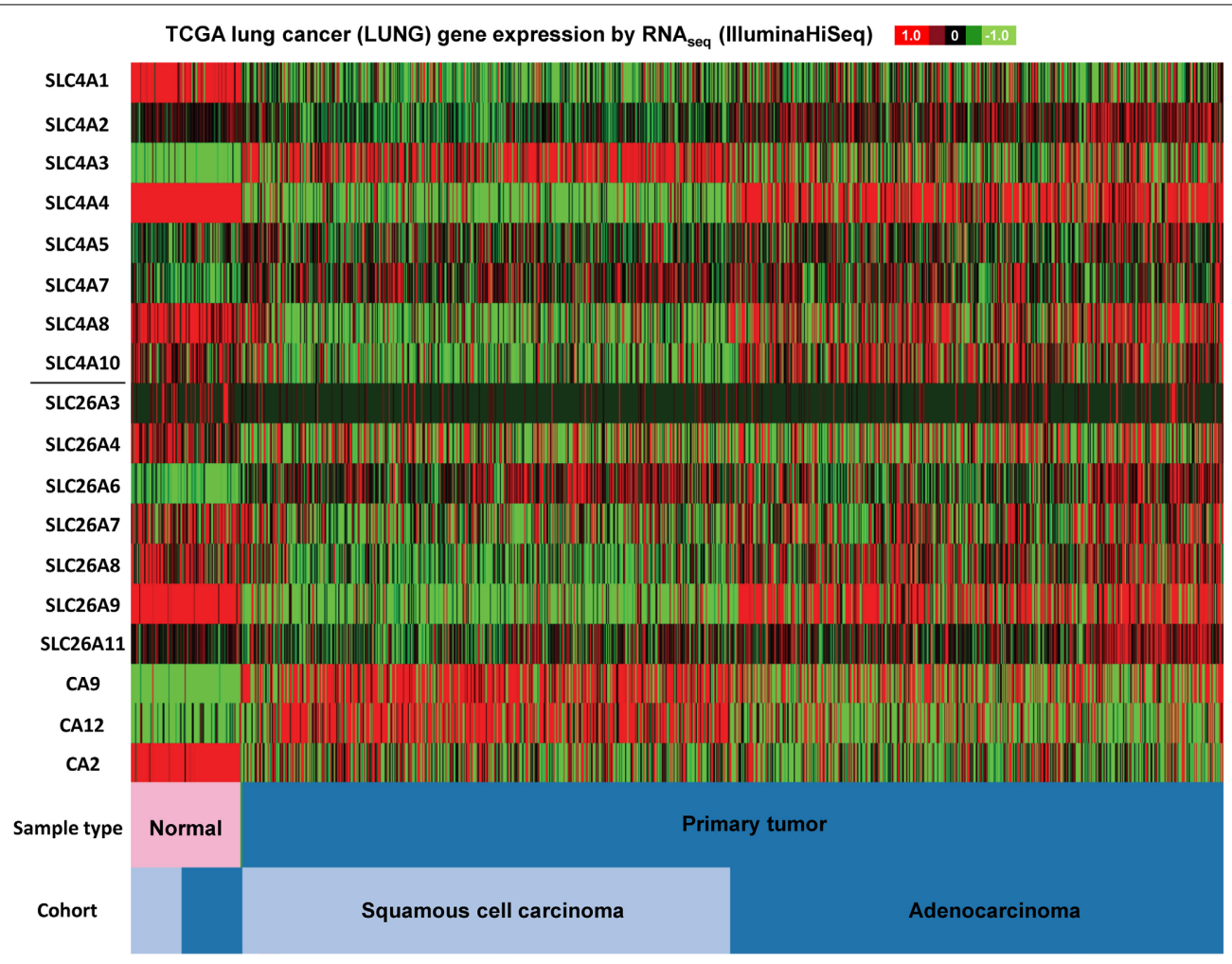

FIGURE 3 | SLC4 and SLC26 family mRNA expression levels in lung cancer. RNA sequencing data (ID: TCGA_LUNG_exp_HiSeqV2, $N=1081$ ) from The Genome Cancer Atlas database was processed and visualized with UCSC Cancer Genomics Browser (https://genome-cancer.ucsc.edu). The color scale represents changes of gene expression: up-regulation (red) down-regulation (green) or no change (black). Data is expressed as log2 transformed RNA-seq RSEM counts normalized to log2 transformed mean of the dataset.
SLC26A9 are down-regulated in squamous cell carcinoma, but not in adenocarcinoma of the lung.

The different subtypes of breast cancer (Figure 4) show an even more heterogeneous expression pattern of SLC4 and SLC26 family transporters. Especially basal breast cancers are distinct from the other subtypes, with markedly different expression patterns of many of these proteins compared to the other subtypes, including an apparent strong and consistent upregulation of SLC26A9. However, some general trends are observed across all breast cancer subtypes: SLC4A1, SLC4A4, SLC26A3, and SLC26A4 seem to be consistently down-regulated, while SLC4A5 is up-regulated, in all breast cancer subtypes compared to normal breast tissue. Of note, the TCGA data show no consistent upregulation of SLC4A7 mRNA levels in cancer, which is at variance with the pattern indicated from protein level data in (Boedtkjer et al., 2013).

Finally, in colon adenocarcinomas (Figure 5), the TCGA data indicate that mRNA levels of SLC4A1, SLC4A4, SLC4A10, SLC26A3, SLC26A4, and SLC26A7 are down-regulated, while SLC4A2 and SLC4A5 tend to be up-regulated, compared to normal colon tissue. Thus, consistent with published findings [see section Down-Regulated in Adenoma (SLC26A3, DRA)], SLC26A3 is down-regulated in colon cancer, but furthermore, our analyses reveal that this gene is also widely down-regulated in breast cancer (Figure 4).
Interesting patterns are also seen when comparing the expression patterns of three carbonic anhydrases implicated in cancer development: CAII, CAIX, and CAXII, to each other and to that of the $\mathrm{HCO}_{3}^{-}$transporters. Firstly, while CAII mRNA levels are generally down-regulated through lung and colon cancer datasets (less so in breast cancer), CAIX and CAXII seem to be expressed in a highly cancer subtype-specific manner. For instance, the CAIX mRNA level is strongly increased in basal and triple-negative breast cancers, while the CAXII mRNA level is generally increased in all breast cancer subtypes except the triple-negative breast cancers. Also interestingly, the mRNA levels of both CAIX and CAXII are increased in squamous cell carcinoma of the lung, yet not in lung adenocarcinomas. Second, marked co-expression patterns are notable between specific CAs and specific $\mathrm{HCO}_{3}^{-}$transporters. For instance, the high levels of CAIX and CAXII in squamous cell carcinomas and low levels in adenocarcinoma is accompanied by an almost opposite expression pattern of the $\mathrm{HCO}_{3}^{-}$transporters, levels of which are generally high in adenocarcinoma and low in squamous cell carcinoma, the only exception being SLC4A3. Another example is the expression pattern of SLC26A9 and CAIX in breast cancer, which is strikingly similar, with high levels in basal and triple-negative breast cancers only. While this of course needs further, unequivocal validation, we hypothesize that such distinct patterns might be useful in the differentiation between specific cancer subtypes, both in breast and lung cancer. 


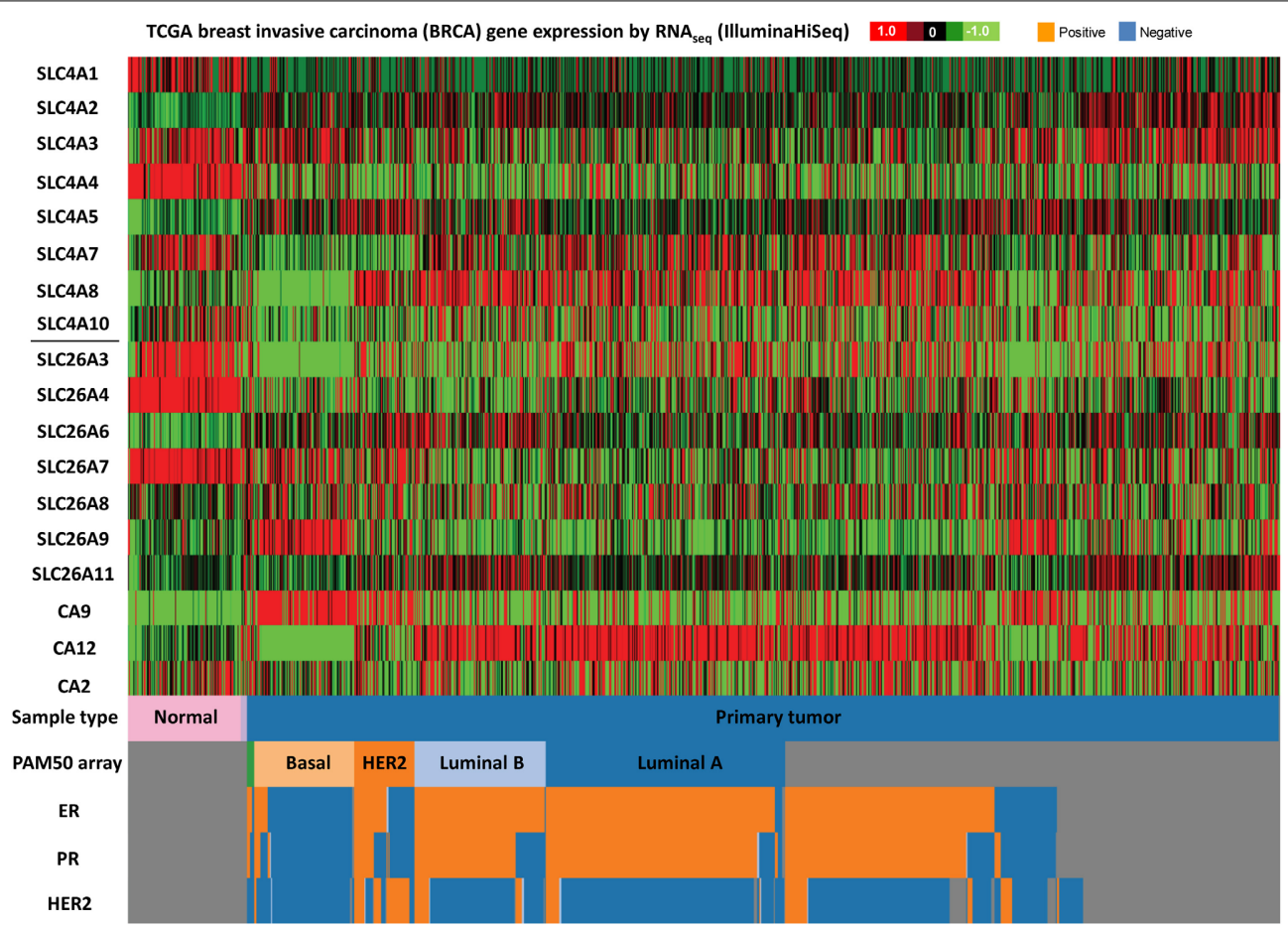

FIGURE 4 | SLC4 and SLC26 family mRNA expression levels in breast cancer. RNA sequencing data (ID: TCGA_BRCA_exp_HiSeqV2, $N=1106$ ) from The Genome Cancer Atlas database was processed and visualized with UCSC Cancer Genomics Browser (https://genome-cancer.ucsc.edu). The color scale represents changes of gene expression: up-regulation (red), down-regulation (green) or no change (black). Data is expressed as log2 transformed RNA-seq RSEM counts normalized to log2 transformed mean of the dataset.
The juxtaposition of all the $\mathrm{HCO}_{3}^{-}$transporter expression data in Figures 3-5 begs the question of whether there are patterns reflecting the functional categories of transporters, i.e., anion exchangers vs. $\mathrm{Na}^{+}$-coupled 1:1 or 1:2 $\mathrm{HCO}_{3}^{-}$transporters. In general, however, apart from co-expression patterns like those described above, no strong such pattern emerges. Collectively, our analyses of publicly available gene expression data confirm the notion that many $\mathrm{HCO}_{3}^{-}$transporters exhibit markedly altered expression patterns in cancer compared to normal tissue. However, the data does not reveal an explicit trend consistent with the notion that $\mathrm{HCO}_{3}^{-}$extruders would be down-regulated and $\mathrm{HCO}_{3}^{-}$loaders up-regulated in solid tumors. Moreover, different subtypes of the cancers studied exhibit different $\mathrm{HCO}_{3}^{-}$ transporter expression profiles, in congruence with the known heterogeneity of genetic and epigenetic changes in cancer. Finally and importantly, these data reveal nothing about the possible posttranslational regulation of these transporters, which could result in an activity profile completely different from the expression profile. It seems likely that the specific $\mathrm{HCO}_{3}^{-}$transporter(s) expressed might be subject to great variance between cancer types and subtypes, whereas the functional correlate-increased net acid extrusion capacity — would be more similar. However, also at the functional level, substantial differences are expected, depending, e.g., on metabolic differences between cancer types. Future studies should focus on revealing the mechanisms of regulation of $\mathrm{HCO}_{3}^{-}$transporter expression and activity and the possible functional relevance of the changes observed here, for cancer development. Given the increasing evidence pointing toward a major importance of $\mathrm{pH}$-regulatory ion transport dysregulation in cancer development, we hypothesize that altered $\mathrm{HCO}_{3}^{-}$transporter expression, if paralleled by increased activity, is likely to play a causal role in at least some cancers, and hence, that these transporters are potentially relevant as therapeutic targets.

\section{CONCLUSIONS AND OUTLOOK}

While the great majority of the research on the roles of $\mathrm{pH}_{\mathrm{i}}$ dysregulation in cancer development has focused on $\mathrm{H}^{+}$transport, recent evidence indicates that also $\mathrm{HCO}_{3}^{-}$transport is dysregulated in many cancers. The few studies available to date addressing the importance of $\mathrm{HCO}_{3}^{-}$transport for $\mathrm{pH}_{\mathrm{i}}$ regulation and cancer cell growth show that particularly under $3 \mathrm{D}$ conditions, $\mathrm{HCO}_{3}^{-}$ transport appears to play a central role. The new datamining analyses presented here suggests that many more $\mathrm{HCO}_{3}^{-}$transporters than those studied to date may be dysregulated in various cancers, and we hypothesize that this may have both diagnostic and therapeutic potential. However, most of the central questions remain open, including the mechanisms of transporter dysregulation, the possible causal role of the dysregulation for cancer development, and the extent to which such a role reflects the involvement of the transporters in $\mathrm{pH}_{\mathrm{i}}$ regulation. Furthermore, it will be essential to validate the putative roles of $\mathrm{HCO}_{3}^{-}$transporters in in vivo models of cancer. 


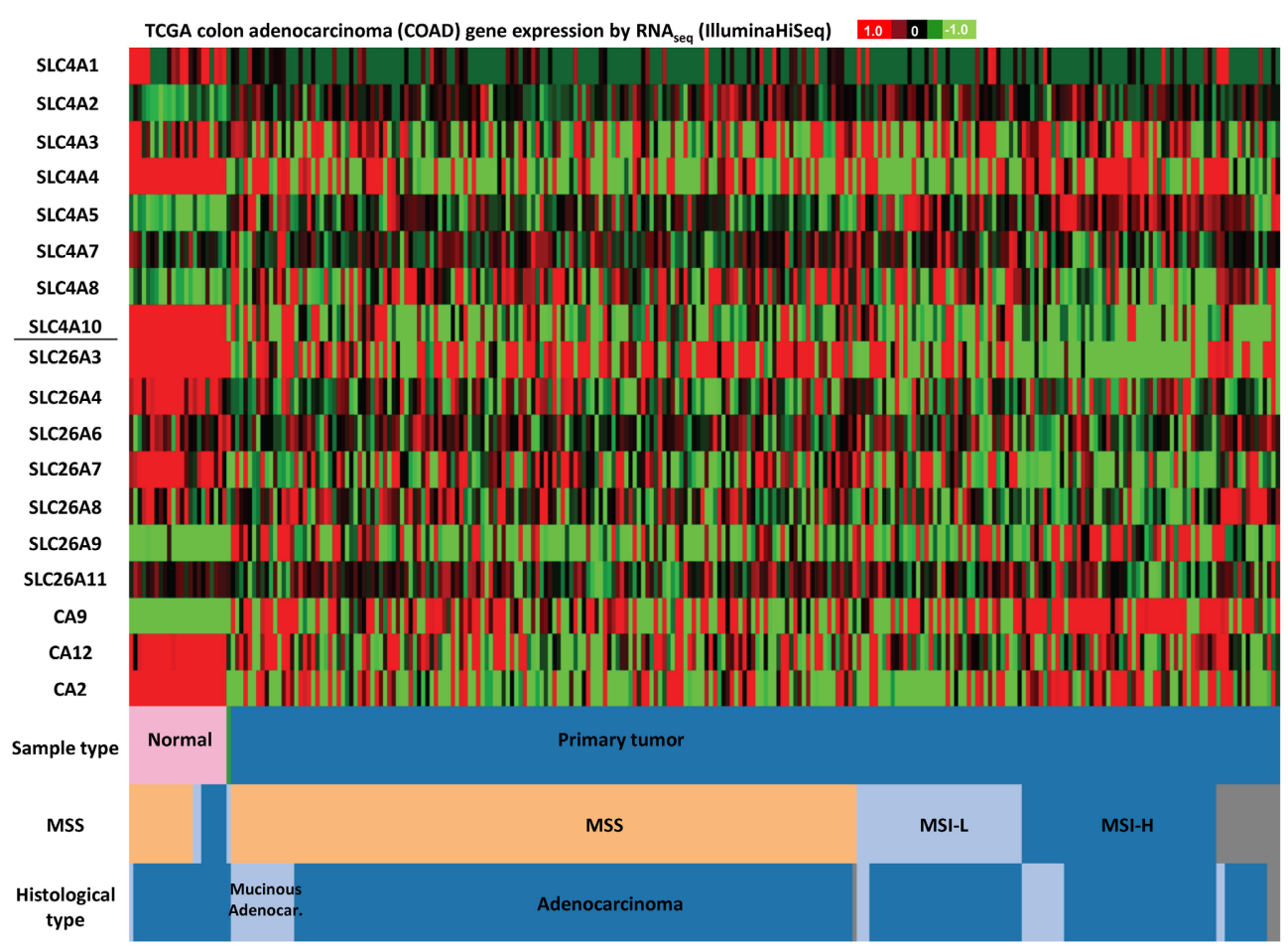

FIGURE 5 | SLC4 and SLC26 family mRNA expression levels in colorectal cancer. RNA sequencing data (ID: TCGA_COAD_exp_HiSeqV2, $N=272$ ) from The Genome Cancer Atlas database was processed and visualized with UCSC Cancer Genomics Browser (https://genome-cancer.ucsc.edu). The color scale represents changes of gene expression: up-regulation (red color), down-regulation (green) or no change (black). Data is expressed as log2 transformed RNA-seq RSEM counts normalized to log2 transformed mean of the dataset.

\section{REFERENCES}

Ahmed, S., Thomas, G., Ghoussaini, M., Healey, C. S., Humphreys, M. K., Platte, R., et al. (2009). Newly discovered breast cancer susceptibility loci on 3p24 and 17q23.2. Nat. Genet. 41, 585-590. doi: 10.1038/ng.354

Alper, S. L., and Sharma, A. K. (2013). The SLC26 gene family of anion transporters and channels. Mol. Aspects Med. 34, 494-515. doi: 10.1016/j.mam.2012.07.009

Andersen, A. P., Moreira, J., and Pedersen, S. F. (2014). Interactions of ion transporters and channels with cancer cell metabolism and the tumor microenvironment. Philos. Trans. R. Soc. Lond. B Biol. Sci. 369:20130098. doi: 10.1098/rstb.2013.0098

Andrew, A. S., Gui, J., Sanderson, A. C., Mason, R. A., Morlock, E. V., Schned, A. R., et al. (2009). Bladder cancer SNP panel predicts susceptibility and survival. Hum. Genet. 125, 527-539. doi: 10.1007/s00439-009-0645-6

Antalis, T. M., Reeder, J. A., Gotley, D. C., Byeon, M. K., Walsh, M. D., Henderson, K. W., et al. (1998). Down-regulation of the down-regulated in adenoma (DRA) gene correlates with colon tumor progression. Clin. Cancer Res. 4, 1857-1863.

Arturi, F., Russo, D., Bidart, J. M., Scarpelli, D., Schlumberger, M., and Filetti, S. (2001). Expression pattern of the pendrin and sodium/iodide symporter genes in human thyroid carcinoma cell lines and human thyroid tumors. Eur. J. Endocrinol. 145, 129-135. doi: 10.1530/eje.0.1450129

Baker, J. B., Dutta, D., Watson, D., Maddala, T., Munneke, B. M., Shak, S., et al. (2011). Tumour gene expression predicts response to cetuximab in patients with KRAS wild-type metastatic colorectal cancer. Br. J. Cancer 104, 488-495. doi: 10.1038/sj.bjc.6606054

Bartosova, M., Parkkila, S., Pohlodek, K., Karttunen, T. J., Galbavy, S., Mucha, V. et al. (2002). Expression of carbonic anhydrase IX in breast is associated with malignant tissues and is related to overexpression of c-erbB2. J. Pathol. 197, 314-321. doi: 10.1002/path.1120

Belickova, M., Merkerova, M. D., Stara, E., Vesela, J., Sponerova, D., Mikulenkova, D., et al. (2013). DNA repair gene variants are associated with an increased risk of myelodysplastic syndromes in a Czech population. J. Hematol. Oncol. 6, 9. doi: $10.1186 / 1756-8722-6-9$
Boedtkjer, E., and Aalkjaer, C. (2013). Acid-base transporters modulate cell migration, growth and proliferation: implications for structure development and remodeling of resistance arteries? Trends Cardiovasc. Med. 23, 59-65. doi: 10.1016/j.tcm.2012.09.001

Boedtkjer, E., Bunch, L., and Pedersen, S. F. (2012). Physiology, pharmacology and pathophysiology of the $\mathrm{pH}$ regulatory transport proteins $\mathrm{NHE} 1$ and $\mathrm{NBCn} 1$ : similarities, differences, and implications for cancer therapy. Curr. Pharm. Des. 18, 1345-1371. doi: 10.2174/138161212799504830

Boedtkjer, E., Moreira, J. M., Mele, M., Vahl, P., Wielenga, V. T., Christiansen, P. M., et al. (2013). Contribution of $\mathrm{Na}+, \mathrm{HCO} 3(-)$-cotransport to cellular $\mathrm{pH}$ control in human breast cancer: a role for the breast cancer susceptibility locus NBCn1 (SLC4A7). Int. J. Cancer 132, 1288-1299. doi: 10.1002/ ijc. 27782

Boedtkjer, E., Praetorius, J., Fuchtbauer, E. M., and Aalkjaer, C. (2008). Antibodyindependent localization of the electroneutral $\mathrm{Na}^{+}-\mathrm{HCO}_{3}^{-}$cotransporter NBCn1 (slc4a7) in mice. AJP Cell Physiol. 294, C591-C603. doi: 10.1152/ajpcell.00281.2007

Boedtkjer, E., Praetorius, J., Matchkov, V. V., Stankevicius, E., Mogensen, S. Füchtbauer, A. C., et al. (2011). Disruption of $\mathrm{Na}^{+}, \mathrm{HCO}_{3}^{-}$-cotransporter NBCn1 (slc4a7) inhibits NO-mediated vasorelaxation, smooth muscle $\mathrm{Ca}^{2+}$. sensitivity and hypertension development in mice. Circulation 124, 1819-1824. doi: 10.1161/CIRCULATIONAHA.110.015974

Boron, W. F., and Boulpaep, E. L. (1989). The electrogenic Na/HCO3 cotransporter Kidney Int. 36, 392-402. doi: 10.1038/ki.1989.208

Cairns, R. A., Harris, I. S., and Mak, T. W. (2011). Regulation of cancer cell metabolism. Nat. Rev. Cancer 11, 85-95. doi: 10.1038/nrc2981

Cantor, J. R., and Sabatini, D. M. (2012). Cancer cell metabolism: one hallmark, many faces. Cancer Discov. 2, 881-898. doi: 10.1158/2159-8290.CD-12-0345

Chapman, J. M., Knoepp, S. M., Byeon, M. K., Henderson, K. W., and Schweinfest, C. W. (2002). The colon anion transporter, down-regulated in adenoma, induces growth suppression that is abrogated by E1A. Cancer Res. 62, 5083-5088. 
Chen, J., Rocken, C., Hoffmann, J., Kruger, S., Lendeckel, U., Rocco, A., et al. (2005). Expression of carbonic anhydrase 9 at the invasion front of gastric cancers. Gut 54, 920-927. doi: 10.1136/gut.2004.047340

Chen, W., Zhong, R., Ming, J., Zou, L., Zhu, B., Lu, X., et al. (2012). The SLC4A7 variant rs4973768 is associated with breast cancer risk: evidence from a casecontrol study and a meta-analysis. Breast Cancer Res. Treat. 136, 847-857. doi: 10.1007/s10549-012-2309-9

Chen, Y., Choong, L. Y., Lin, Q., Philp, R., Wong, C. H., Ang, B. K., et al. (2007). Differential expression of novel tyrosine kinase substrates during breast cancer development. Mol. Cell Proteomics 6, 2072-2087. doi: 10.1074/mcp.M700395MCP200

Chiche, J., Ilc, K., Laferriere, J., Trottier, E., Dayan, F., Mazure, N. M., et al. (2009). Hypoxia-inducible carbonic anhydrase IX and XII promote tumor cell growth by counteracting acidosis through the regulation of the intracellular $\mathrm{pH}$. Cancer Res. 69, 358-368. doi: 10.1158/0008-5472.CAN-08-2470

Christianson, T. A., Doherty, J. K., Lin, Y. J., Ramsey, E. E., Holmes, R., Keenan, E. J., et al. (1998). NH2-terminally truncated HER-2/neu protein: relationship with shedding of the extracellular domain and with prognostic factors in breast cancer. Cancer Res. 58, 5123-5129.

Crawford, I., Maloney, P. C., Zeitlin, P. L., Guggino, W. B., Hyde, S. C. Turley, H., et al. (1991). Immunocytochemical localization of the cystic fibrosis gene product CFTR. Proc. Natl. Acad. Sci. U.S.A. 88, 9262-9266. doi: 10.1073/pnas.88.20.9262

Dalerba, P., Kalisky, T., Sahoo, D., Rajendran, P. S., Rothenberg, M. E., Leyrat, A A., et al. (2011). Single-cell dissection of transcriptional heterogeneity in human colon tumors. Nat. Biotechnol. 29, 1120-1127. doi: 10.1038/nbt.2038

Damkier, H. H., Aalkjaer, C., and Praetorius, J. (2010). $\mathrm{Na}^{+}$-dependent $\mathrm{HCO}_{3}^{-}$ import by the slc4a10 gene product involves $\mathrm{Cl}^{-}$export. J. Biol. Chem. 285, 26998-27007. doi: 10.1074/jbc.M110.108712

De Milito, A., Canese, R., Marino, M. L., Borghi, M., Iero, M., Villa, A., et al. (2010). pH-dependent antitumor activity of proton pump inhibitors against human melanoma is mediated by inhibition of tumor acidity. Int. J. Cancer 127 207-219. doi: 10.1002/ijc.25009

de Ronde, J. J., Lips, E. H., Mulder, L., Vincent, A. D., Wesseling, J., Nieuwland, M., et al. (2013). SERPINA6, BEX1, AGTR1, SLC26A3, and LAPTM4B are markers of resistance to neoadjuvant chemotherapy in HER2-negative breast cancer. Breast Cancer Res. Treat. 137, 213-223. doi: 10.1007/s10549-012-2340-x

Estrella, V., Chen, T., Lloyd, M., Wojtkowiak, J., Cornnell, H. H., Ibrahim-Hashim, A., et al. (2013). Acidity generated by the tumor microenvironment drives local invasion. Cancer Res. 73, 1524-1535. doi: 10.1158/0008-5472.CAN-12-2796

Fasching, P. A., Pharoah, P. D., Cox, A., Nevanlinna, H., Bojesen, S. E., Karn, T., et al. (2012). The role of genetic breast cancer susceptibility variants as prognostic factors. Hum. Mol. Genet. 21, 3926-3939. doi: 10.1093/hmg/dds159

Fernandez-Navarro, P., Pita, G., Santamarina, C., Moreno, M. P., Vidal, C., Miranda-Garcia, J., et al. (2013). Association analysis between breast cancer genetic variants and mammographic density in a large population-based study (Determinants of Density in Mammographies in Spain) identifies susceptibility loci in TOX3 gene. Eur. J. Cancer 49, 474-481. doi: 10.1016/j.ejca.2012. 08.026

Forbes, S. A., Bindal, N., Bamford, S., Cole, C., Kok, C. Y., Beare, D., et al. (2011). COSMIC: mining complete cancer genomes in the Catalogue of Somatic Mutations in Cancer. Nucleic Acids Res. 39, D945-D950. doi: 10.1093/nar/gkq929

Galeza-Kulik, M., Zebracka, J., Szpak-Ulczok, S., Czarniecka, A. K., Kukulska, A., Gubala, E., et al. (2006). [Expression of selected genes involved in transport of ions in papillary thyroid carcinoma]. Endokrynol. Pol. 57(Suppl. A), 26-31.

Gatenby, R. A., and Gillies, R. J. (2008). A microenvironmental model of carcinogenesis. Nat. Rev. Cancer 8, 56-61. doi: 10.1038/nrc2255

Gerber, J. M., Gucwa, J. L., Esopi, D., Gurel, M., Haffner, M. C., Vala, M., et al. (2013). Genome-wide comparison of the transcriptomes of highly enriched normal and chronic myeloid leukemia stem and progenitor cell populations. Oncotarget 4, 715-728.

Goldman, M., Craft, B., Swatloski, T., Ellrott, K., Cline, M., Diekhans, M., et al. (2013). The UCSC cancer genomics browser: update 2013. Nucleic Acids Res. 41, D949-D954. doi: 10.1093/nar/gks1008

Gorbatenko, A., Olesen, C. W., Lauritzen, G., Valen, E., and Pedersen, S. F. (2014). Regulation of the $\mathrm{Na}^{+}, \mathrm{HCO}_{3}^{-}$cotransporter NBCn1 (SLC4A7) by a constitutively active ErbB2 receptor in MCF-7 breast cancer cells. FASEB J. 28, 350-363. doi: $10.1096 /$ fj.13-233288
Halestrap, A. P. (2013). The SLC16 gene family - Structure, role and regulation in health and disease. Mol. Aspects Med. 34, 337-349. doi: 10.1016/j.mam.2012.05.003

Han, W., Woo, J. H., Yu, J. H., Lee, M. J., Moon, H. G., Kang, D., et al. (2011). Common genetic variants associated with breast cancer in Korean women and differential susceptibility according to intrinsic subtype. Cancer Epidemiol. Biomarkers Prev. 20, 793-798. doi: 10.1158/1055-9965.EPI-10-1282

Hemminki, A., Hoglund, P., Pukkala, E., Salovaara, R., Jarvinen, H., Norio R., et al. (1998). Intestinal cancer in patients with a germline mutation in the down-regulated in adenoma (DRA) gene. Oncogene 16, 681-684. doi: 10.1038/sj.onc. 1201538

Hoglund, P., Haila, S., Socha, J., Tomaszewski, L., Saarialho-Kere, U., KarjalainenLindsberg, M. L., et al. (1996). Mutations of the Down-regulated in adenoma (DRA) gene cause congenital chloride diarrhoea. Nat. Genet. 14, 316-319. doi: $10.1038 / \mathrm{ng} 1196-316$

Hulikova, A., Harris, A. L., Vaughan-Jones, R. D., and Swietach, P. (2013). Regulation of intracellular $\mathrm{pH}$ in cancer cell lines under normoxia and hypoxia. J. Cell Physiol. 228, 743-752. doi: 10.1002/jcp.24221

Hulikova, A., Vaughan-Jones, R. D., and Swietach, P. (2011). Dual role of $\mathrm{CO}_{2} / \mathrm{HCO}_{3}^{-}$buffer in the regulation of intracellular $\mathrm{pH}$ of three-dimensional tumor growths. J. Biol. Chem. 286, 13815-13826. doi: 10.1074/jbc.M111.219899

Hwang, J. M., Kao, S. H., Hsieh, Y. H., Li, K. L., Wang, P. H., Hsu, L. S. et al. (2009). Reduction of anion exchanger 2 expression induces apoptosis of human hepatocellular carcinoma cells. Mol. Cell Biochem. 327, 135-144. doi: 10.1007/s11010-009-0051-3

Ibrahim-Hashim, A., Cornnell, H. H., Abrahams, D., Lloyd, M., Bui, M., Gillies, R. J., et al. (2012). Systemic buffers inhibit carcinogenesis in TRAMP mice. J. Urol. 188, 624-631. doi: 10.1016/j.juro.2012.03.113

Iwata, T., Yoshida, T., Teranishi, M., Murata, Y., Hayashi, Y., Kanou, Y., et al. (2011) Influence of dietary iodine deficiency on the thyroid gland in Slc26a4-null mutant mice. Thyroid Res. 4, 10. doi: 10.1186/1756-6614-4-10

Jacob, P., Rossmann, H., Lamprecht, G., Kretz, A., Neff, C., Lin-Wu, E., et al. (2002). Down-regulated in adenoma mediates apical Cl-/HCO3- exchange in rabbit, rat, and human duodenum. Gastroenterology 122, 709-724. doi: 10.1053/gast.2002.31875

Kim, H. S., Kim, d. H., Kim, J. Y., Jeoung, N. H., Lee, I. K., Bong, J. G., et al. (2010). Microarray analysis of papillary thyroid cancers in Korean. Korean J. Intern. Med. 25, 399-407. doi: 10.3904/kjim.2010.25.4.399

Kroemer, G., and Pouyssegur, J. (2008). Tumor cell metabolism: cancer's Achilles' heel. Cancer Cell 13, 472-482. doi: 10.1016/j.ccr.2008.05.005

Lauriola, M., Ugolini, G., Rosati, G., Zanotti, S., Montroni, I., Manaresi, A., et al. (2010). Identification by a Digital Gene Expression Displayer (DGED) and test by RT-PCR analysis of new mRNA candidate markers for colorectal cancer in peripheral blood. Int. J. Oncol. 37, 519-525. doi: 10.3892/ijo_00000701

Lauritzen, G., Jensen, M. B., Boedtkjer, E., Dybboe, R., Aalkjaer, C., Nylandsted, J., et al. (2010). NBCn1 and NHE1 expression and activity in $\triangle$ NErbB2 receptor-expressing MCF-7 breast cancer cells: contributions to $\mathrm{pHi}$ regulation and chemotherapy resistance. Exp. Cell Res. 316, 2538-2553. doi: 10.1016/j.yexcr.2010.06.005

Lauritzen, G., Stock, C. M., Lemaire, J., Lund, S. F., Jensen, M. F., Damsgaard, B., et al. (2012). The $\mathrm{Na}^{+} / \mathrm{H}^{+}$exchanger $\mathrm{NHE1}$, but not the $\mathrm{Na}^{+}$, $\mathrm{HCO}_{3}^{-}$cotransporter NBCn1, regulates motility of MCF7 breast cancer cells expressing constitutively active ErbB2. Cancer Lett. 317, 172-183. doi: 10.1016/j.canlet.2011.11.023

Long, J., Shu, X. O., Cai, Q., Gao, Y. T., Zheng, Y., Li, G., et al. (2010). Evaluation of breast cancer susceptibility loci in Chinese women. Cancer Epidemiol. Biomarkers Prev. 19, 2357-2365. doi: 10.1158/1055-9965.EPI-10-0054

Martin, N. K., Robey, I. F., Gaffney, E. A., Gillies, R. J., Gatenby, R. A., and Maini, P. K. (2012). Predicting the safety and efficacy of buffer therapy to raise tumour pHe: an integrative modelling study. Br. J. Cancer 106, 1280-1287. doi: 10.1038/bjc. 2012.58

Matias-Guiu, X., and Prat, J. (2013). Molecular pathology of endometrial carcinoma. Histopathology 62, 111-123. doi: 10.1111/his.12053

Mencia, N., Selga, E., Noe, V., and Ciudad, C. J. (2011). Underexpression of miR224 in methotrexate resistant human colon cancer cells. Biochem. Pharmacol. 82, 1572-1582. doi: 10.1016/j.bcp.2011.08.009

Millar, I. D., and Brown, P. D. (2008). NBCe2 exhibits a $3 \mathrm{HCO}_{3}^{-}: 1 \mathrm{Na}^{+}$stoichiometry in mouse choroid plexus epithelial cells. Biochem. Biophys. Res. Commun 373, 550-554. doi: 10.1016/j.bbrc.2008.06.053 
Mosakhani, N., Lahti, L., Borze, I., Karjalainen-Lindsberg, M. L., Sundstrom, J., Ristamaki, R., et al. (2012). MicroRNA profiling predicts survival in anti-EGFR treated chemorefractory metastatic colorectal cancer patients with wild-type KRAS and BRAF. Cancer Genet. 205, 545-551. doi: 10.1016/j.cancergen.2012.08.003

Mulligan, A. M., Couch, F. J., Barrowdale, D., Domchek, S. M., Eccles, D., Nevanlinna, H., et al. (2011). Common breast cancer susceptibility alleles are associated with tumour subtypes in BRCA1 and BRCA2 mutation carriers: results from the Consortium of Investigators of Modifiers of BRCA1/2. Breast Cancer Res. 13, R110. doi: 10.1186/bcr3052

Padua, R. A., Warren, N., Grimshaw, D., Smith, M., Lewis, C., Whittaker, J., et al. (1997). The cystic fibrosis delta F508 gene mutation and cancer. Hum. Mutat. 10, 45-48. doi: 10.1002/(SICI)1098-1004(1997)10:1<45::AIDHUMU6>3.0.CO;2-L

Parker, M. D., and Boron, W. F. (2013). The divergence, actions, roles, and relatives of sodium-coupled bicarbonate transporters. Physiol. Rev. 93, 803-959. doi: 10.1152/physrev.00023.2012

Parker, M. D., Musa-Aziz, R., Rojas, J. D., Choi, I., Daly, C. M., and Boron, W. F. (2008). Characterization of human SLC4A10 as an electroneutral $\mathrm{Na} / \mathrm{HCO}_{3}$ cotransporter $(\mathrm{NBCn} 2)$ with $\mathrm{Cl}^{-}$self-exchange activity. J. Biol. Chem. 283, 12777-12788. doi: 10.1074/jbc.M707829200

Parks, S. K., Chiche, J., and Pouyssegur, J. (2013). Disrupting proton dynamics and energy metabolism for cancer therapy. Nat. Rev. Cancer 13, 611-623. doi: $10.1038 / \mathrm{nrc} 3579$

Pedersen, S. F., and Stock, C. (2013). Ion channels and transporters in cancer: pathophysiology, regulation, and clinical potential. Cancer Res. 73, 1658-1661. doi: 10.1158/0008-5472.CAN-12-4188

Perez-Sayans, M., Suarez-Penaranda, J. M., Pilar, G. D., Supuran, C. T., Pastorekova, S., Barros-Angueira, F., et al. (2012). Expression of CA-IX is associated with advanced stage tumors and poor survival in oral squamous cell carcinoma patients. J. Oral. Pathol. Med. 41, 667-674. doi: 10.1111/j.16000714.2012.01147.x

Porra, V., Bernier-Valentin, F., Trouttet-Masson, S., Berger-Dutrieux, N., Peix, J. L., Perrin, A., et al. (2002). Characterization and semiquantitative analyses of pendrin expressed in normal and tumoral human thyroid tissues. J. Clin. Endocrinol. Metab. 87, 1700-1707. doi: 10.1210/jcem.87.4.8372

Reshkin, S. J., Bellizzi, A., Caldeira, S., Albarani, V., Malanchi, I., Poignee, M., et al. (2000). $\mathrm{Na}^{+} / \mathrm{H}^{+}$exchanger-dependent intracellular alkalinization is an early event in malignant transformation and plays an essential role in the development of subsequent transformation-associated phenotypes. FASEB J. 14, 2185-2197. doi: 10.1096/fj.00-0029com

Reshkin, S. J., Cardone, R. A., and Harguindey, S. (2013). $\mathrm{Na}^{+}-\mathrm{H}^{+}$exchanger, $\mathrm{pH}$ regulation and cancer. Recent Pat. Anticancer Drug Discov. 8, 85-99. doi: $10.2174 / 1574892811308010085$

Ro, H. A., and Carson, J. H. (2004). pH microdomains in oligodendrocytes. J. Biol. Chem. 279, 37115-37123. doi: 10.1074/jbc.M403099200

Robey, I. F., Baggett, B. K., Kirkpatrick, N. D., Roe, D. J., Dosescu, J., Sloane, B. F., et al. (2009). Bicarbonate increases tumor $\mathrm{pH}$ and inhibits spontaneous metastases. Cancer Res. 69, 2260-2268. doi: 10.1158/0008-5472.CAN07-5575

Robey, I. F., and Nesbit, L. A. (2013). Investigating mechanisms of alkalinization for reducing primary breast tumor invasion. Biomed. Res. Int. 2013, 485196 doi: 10.1155/2013/485196

Romero, M. F., Chen, A. P., Parker, M. D., and Boron, W. F. (2013). The SLC4 family of bicarbonate $\left(\mathrm{HCO}_{3}^{-}\right)$transporters. Mol. Aspects Med. 34, 159-182. doi: 10.1016/j.mam.2012.10.008

Rotin, D., Steele-Norwood, D., Grinstein, S., and Tannock, I. (1989). Requirement of the $\mathrm{Na}+/ \mathrm{H}+$ exchanger for tumor growth. Cancer Res. 49, 205-211.

Schwab, A., Fabian, A., Hanley, P. J., and Stock, C. (2012). Role of ion channels and transporters in cell migration. Physiol. Rev. 92, 1865-1913. doi: 10.1152/physrev.00018.2011

Schwab, A., Rossmann, H., Klein, M., Dieterich, P., Gassner, B., Neff, C., et al. (2005). Functional role of $\mathrm{Na}^{+}-\mathrm{HCO}_{3}^{-}$cotransport in migration of transformed renal epithelial cells. J. Physiol. 568, 445-458. doi: 10.1113/jphysiol.2005. 092957

Schweinfest, C. W., Henderson, K. W., Suster, S., Kondoh, N., and Papas, T. S. (1993). Identification of a colon mucosa gene that is down-regulated in colon adenomas and adenocarcinomas. Proc. Natl. Acad. Sci. U.S.A. 90, 4166-4170. doi: 10.1073/pnas.90.9.4166
Schweinfest, C. W., Spyropoulos, D. D., Henderson, K. W., Kim, J. H., Chapman, J. M., Barone, S., et al. (2006). slc26a3 (dra)-deficient mice display chloridelosing diarrhea, enhanced colonic proliferation, and distinct up-regulation of ion transporters in the colon. J. Biol. Chem. 281, 37962-37971. doi: 10.1074/jbc.M607527200

Sennoune, S. R., Bakunts, K., Martinez, G. M., Chua-Tuan, J. L., Kebir, Y., Attaya, M. N., et al. (2004). Vacuolar H+-ATPase in human breast cancer cells with distinct metastatic potential: distribution and functional activity. Am. J. Physiol. Cell Physiol. 286, C1443-C1452. doi: 10.1152/ajpcell.00407.2003

Shen, W. W., Wu, J., Cai, L., Liu, B. Y., Gao, Y., Chen, G. Q., et al. (2007). Expression of anion exchanger 1 sequestrates p16 in the cytoplasm in gastric and colonic adenocarcinoma. Neoplasia 9, 812-819. doi: 10.1593/neo.07403

Silva, A. S., Yunes, J. A., Gillies, R. J., and Gatenby, R. A. (2009). The potential role of systemic buffers in reducing intratumoral extracellular $\mathrm{pH}$ and acid-mediated invasion. Cancer Res. 69, 2677-2684. doi: 10.1158/0008-5472.CAN-08-2394

Song, L. J., Liu, R. J., Zeng, Z., Alper, S. L., Cui, H. J., Lu, Y., et al. (2012). Gastrin inhibits a novel, pathological colon cancer signaling pathway involving EGR1, AE2, and P-ERK. J. Mol. Med. (Berl.) 90, 707-718. doi: 10.1007/s00109-0110851-2

Sonveaux, P., Vegran, F., Schroeder, T., Wergin, M. C., Verrax, J., Rabbani, Z. N., et al. (2008). Targeting lactate-fueled respiration selectively kills hypoxic tumor cells in mice. J. Clin. Invest. 118, 3930-3942. doi: 10.1172/JCI36843

Stock, C., and Schwab, A. (2006). Role of the Na+/H+ exchanger NHE1 in cell migration. Acta Physiol. 187, 149-157. doi: 10.1111/j.1748-1716.2006.01543.x

Sueta, A., Ito, H., Kawase, T., Hirose, K., Hosono, S., Yatabe, Y., et al. (2012). A genetic risk predictor for breast cancer using a combination of low-penetrance polymorphisms in a Japanese population. Breast Cancer Res. Treat. 132, 711-721. doi: 10.1007/s10549-011-1904-5

Suo, W. H., Zhang, N., Wu, P. P., Zhao, L., Song, L. J., Shen, W. W., et al. (2012). Anti-tumour effects of small interfering RNA targeting anion exchanger 1 in experimental gastric cancer. Br. J. Pharmacol. 165, 135-147. doi: 10.1111/j.14765381.2011.01521.x

Supuran, C. T. (2008). Carbonic anhydrases-an overview. Curr. Pharm. Des. 14 603-614. doi: 10.2174/138161208783877884

Takahashi, E., Abe, J., Gallis, B., Aebersold, R., Spring, D. J., Krebs, E. G., et al. (1999). p90(RSK) is a serum-stimulated $\mathrm{Na}^{+} / \mathrm{H}^{+}$exchanger isoform-1 kinase. Regulatory phosphorylation of serine 703 of $\mathrm{Na}^{+} / \mathrm{H}^{+}$exchanger isoform-1. J. Biol. Chem. 274, 20206-20214. doi: 10.1074/jbc.274.29.20206

Tian, H., Zhang, N., Suo, W. H., Wang, T., Song, L. J., Wu, J., et al. (2010). Gastrin suppresses the interdependent expression of p16 and anion exchanger 1 favoring growth inhibition of gastric cancer cells. Int. J. Cancer 127, 1462-1474. doi: 10.1002/ijc. 25124

Tokuhiro, S., Yamada, R., Chang, X., Suzuki, A., Kochi, Y., Sawada, T., et al. (2003). An intronic SNP in a RUNX1 binding site of SLC22A4, encoding an organic cation transporter, is associated with rheumatoid arthritis. Nat. Genet. 35, 341-348. doi: 10.1038/ng1267

Vaupel, P. (2004). Tumor microenvironmental physiology and its implications for radiation oncology. Semin. Radiat. Oncol. 14, 198-206. doi: 10.1016/j.semradonc.2004.04.008

Vaupel, P. W., Frinak, S., and Bicher, H. I. (1981). Heterogeneous oxygen partial pressure and $\mathrm{pH}$ distribution in $\mathrm{C} 3 \mathrm{H}$ mouse mammary adenocarcinoma. Cancer Res. 41, 2008-2013.

Virkki, L. V., Wilson, D. A., Vaughan-Jones, R. D., and Boron, W. F. (2002). Functional characterization of human NBC4 as an electrogenic $\mathrm{Na}^{+}-\mathrm{HCO}_{3}^{-}$ cotransporter (NBCe2). Am. J. Physiol. Cell Physiol. 282, C1278-C1289. doi: 10.1152/ajpcell.00589.2001

Wang, T., Zhao, L., Yang, Y., Tian, H., Suo, W. H., Yan, M., et al. (2013). EGR1 is critical for gastrin-dependent upregulation of anion exchanger 2 in gastric cancer cells. FEBS J. 280, 174-183. doi: 10.1111/febs.12058

Webb, B. A., Chimenti, M., Jacobson, M. P., and Barber, D. L. (2011). Dysregulated pH: a perfect storm for cancer progression. Nat. Rev. Cancer 11, 671-677. doi: $10.1038 / \mathrm{nrc} 3110$

Wojtkowiak, J. W., Verduzco, D., Schramm, K. J., and Gillies, R. J. (2011). Drug resistance and cellular adaptation to tumor acidic $\mathrm{pH}$ microenvironment. Mol. Pharm. 8, 2032-2038. doi: 10.1021/mp200292c

Wu, J., Zhang, Y. C., Suo, W. H., Liu, X. B., Shen, W. W., Tian, H., et al. (2010). Induction of anion exchanger- 1 translation and its opposite roles in the carcinogenesis of gastric cancer cells and differentiation of K562 cells. Oncogene 29, 1987-1996. doi: 10.1038/onc.2009.481 
Wu, T. T., Hsieh, Y. H., Wu, C. C., Tsai, J. H., Hsieh, Y. S., Huang, C. Y., et al. (2006). Overexpression of anion exchanger 2 in human hepatocellular carcinoma. Chin. J. Physiol. 49, 192-198.

Xing, M., Tokumaru, Y., Wu, G., Westra, W. B., Ladenson, P. W., and Sidransky, D. (2003). Hypermethylation of the Pendred syndrome gene SLC26A4 is an early event in thyroid tumorigenesis. Cancer Res. 63, 2312-2315.

Xu, W. Q., Song, L. J., Liu, Q., Zhao, L., Zheng, L., Yan, Z. W., et al. (2009). Expression of anion exchanger 1 is associated with tumor progress in human gastric cancer. J. Cancer Res. Clin. Oncol. 135, 1323-1330. doi: 10.1007/s00432009-0573-9

Yang, Y., Wu, P. P., Wu, J., Shen, W. W., Wu, Y. L., Fu, A. F., et al. (2008). Expression of anion exchanger 2 in human gastric cancer. Exp. Oncol. 30, 81-87.

Yoshitomi, K., Burckhardt, B. C., and Fromter, E. (1985). Rheogenic sodiumbicarbonate cotransport in the peritubular cell membrane of rat renal proximal tubule. Pflugers Arch. 405, 360-366. doi: 10.1007/BF00595689

You, H., Jin, J., Shu, H., Yu, B., De, M. A., Lozupone, F., et al. (2009). Small interfering RNA targeting the subunit ATP6L of proton pump V-ATPase overcomes chemoresistance of breast cancer cells. Cancer Lett. 280, 110-119. doi: 10.1016/j.canlet.2009.02.023

Yusa, A., Miyazaki, K., Kimura, N., Izawa, M., and Kannagi, R. (2010). Epigenetic silencing of the sulfate transporter gene DTDST induces sialyl Lewisx expression and accelerates proliferation of colon cancer cells. Cancer Res. 70, 4064-4073. doi: 10.1158/0008-5472.CAN-09-2383
Zhu, J., Sanborn, J. Z., Benz, S., Szeto, C., Hsu, F., Kuhn, R. M., et al. (2009). The UCSC cancer genomics browser. Nat. Methods 6, 239-240. doi: 10.1038/nmeth0409-239

Conflict of Interest Statement: The Associate Editor, M. Bevensee, declares that, despite having collaborated with authors S. Pederson and E. Boedtkjer, the review process was handled objectively and no conflict of interest exists. The authors declare that the research was conducted in the absence of any commercial or financial relationships that could be construed as a potential conflict of interest.

Received: 29 October 2013; accepted: 14 March 2014; published online: 16 April 2014. Citation: Gorbatenko A, Olesen CW, Boedtkjer E and Pedersen SF (2014) Regulation and roles of bicarbonate transporters in cancer. Front. Physiol. 5:130. doi: 10.3389/ fphys.2014.00130

This article was submitted to Membrane Physiology and Membrane Biophysics, a section of the journal Frontiers in Physiology.

Copyright (c) 2014 Gorbatenko, Olesen, Boedtkjer and Pedersen. This is an openaccess article distributed under the terms of the Creative Commons Attribution License (CC BY). The use, distribution or reproduction in other forums is permitted, provided the original author(s) or licensor are credited and that the original publication in this journal is cited, in accordance with accepted academic practice. No use, distribution or reproduction is permitted which does not comply with these terms. 